\title{
CHAPTER
}

\section{The wife's protector: a quantitative theory linking contraceptive technology with the decline in marriage ${ }^{\text {is }}$}

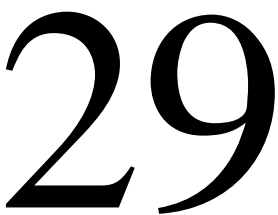

\author{
Jeremy Greenwood ${ }^{\mathrm{a}}$, Nezih Guner ${ }^{\mathrm{b}}$, and Karen A. Kopecky \\ ${ }^{a}$ University of Pennsylvania, Philadelphia, PA, United States \\ ${ }^{b}$ CEMFI, Madrid, Spain \\ ${ }^{c}$ Federal Reserve Bank of Atlanta, Atlanta, GA, United States
}

\subsection{Introduction}

The forward motion of technology is unrelenting. It's hard to think of anything else that has affected the economy and society in such a fundamental way. The Second Industrial Revolution occurred as the clock chimed in the 20th century. It ushered in electricity, the petrochemical industry, and the internal combustion engine. Its ramifications were enormous. Electricity and the internal combustion engine changed the workplace since many manual tasks could now be mechanized. This combined with chemical fertilizers reduced the need for farm labor. Along with the automobile the reduction in the demand for farm labor encouraged the rise of cities and suburbs. Electricity also meant that the home could be mechanized. The mechanization of the home and industry allowed women to enter the labor force. This provided a catalyst for bestowing women's rights in the workplace. ${ }^{1}$

The Information Age (or the Third Industrial Revolution) is also transforming the economy and society. The ENIAC, the first general purpose computer, was set to work at the University of Pennsylvania in 1945. Machines like this were first used in academic and industrial research to perform calculations that were impractical or impossible to do manually. By the 1960s it was apparent that computers could be used to sort, store, process, and retrieve large volumes of data. Networking and the personal computers came online in the 1970s and the 1980s. All of this reduced the need for labor on factory floors, by using numerically controlled machines and flexible manufacturing, and eliminated the need for battalions of clerks, pools of secretaries, scores of purchasing and sales agents, and layers of supervisors and administrators. The recent rise of artificial intelligence is reducing the need for routine mental labor. The information age has also changed the household. Think about the hours saved

\footnotetext{
Dedicated to Stanley L. Engerman, one of the great economic historians. The authors thank Jordan Herring and Yueyuan Ma for research assistance. The title refers to John B. Beers's 1846 Wife's Protector contraceptive device.

1 The impact of technology on family life is the subject of the prescient book by Ogburn and Nimkoff (1955) and more recently by Greenwood (2019).
} 


\section{Chapter 29 The wife's protector}

from online shopping. Telecommuting allows parents to stay home with their children. People can now keep in touch easier with family and friends via social media and telecommuting, so distance matters less. Online dating has made it easier for singles to find mates. ${ }^{2}$

Seemingly small inventions can also have a huge impact on the economy and society. Take, for instance, the discovery of penicillin in 1928 by Sir Alexander Fleming, which was the dawning of the antibiotic era. The leading causes of death in the United States changed from infectious illnesses (cholera, diphtheria, pneumonia, smallpox, typhoid fever, plague, syphilis, tuberculosis, typhus) to noninfectious ones (cardiovascular disease, cancer, and stroke). At the beginning of the 20th century life expectancy was 47 years compared with 79 years today. Better health and longer lives have affected educational attainment, labor-force participation, retirement, and savings. Contraception is another small invention with profound implications.

Technological innovations such as these can be analyzed using quantitative theory. Quantitativetheoretic history aims to develop economic models of historical issues. The models generally start at the level of profit maximization by firms and/or utility maximization by individuals and then aggregate up to get a description of the economy as a whole. There are several key ingredients in this approach. First, is posing an interesting historical question. Second, is providing an historical narrative for the question's background. Third, is the development of an economic model to address the question. Fourth, is analyzing the model to glean intuition about its mechanics and establish any theoretical propositions. Fifth, is simulating the model to see if it can deliver a viable explanation of the historical data surrounding the question of interest. The analysis may end there but often counterfactual experiments are entertained. Hence, quantitative theory can take data and ideas from economic history and address them using the tool kit of modern macroeconomics. The question to be addressed here is: How did technological progress in contraception influence the decline in marriage over the course of the 20th century? The analysis will follow the above five steps.

\subsubsection{Quantitative-theoretic history: some examples}

Early examples using quantitative theory to address historical questions are Cooley and Ohanian (1997), Greenwood and Yorukoglu (1997), and Ohanian (1997). Cooley and Ohanian (1997) and Ohanian (1997) study whether it would have been better to finance World War II by debt or taxation. Their finding is that raising taxation in war times, as Keynes suggested, is a bad idea. Greenwood and Yorukoglu (1997) study three industrial revolutions and find that they are characterized by plunging prices for new technologies, productivity slowdowns, and rising income inequality. They model these phenomena.

Some more recent examples are Cole and Ohanian (2004), Greenwood et al. (2005a), Hansen and Prescott (2002), Kopecky (2011), Kopecky and Suen (2010), and Vandenbroucke (2008). Cole and Ohanian (2004) argue that Roosevelt's New Deal policies, by strengthening the power of monopolies and unions, prolonged the Great Depression. This is in stark contrast with the conventional fawning view of the New Deal. The secular decline in U.S. fertility from 1800, which was briefly interrupted by the baby boom, is addressed in Greenwood et al. (2005a). The transition from the preindustrial to the industrial era is modeled by Hansen and Prescott (2002), who emphasize the switch from land-intensive

2 Billari (2019) reports that in 2017 nearly 40 percent of heterosexual couples met online. 
to capital-intensive production technologies. Caucutt et al. (2013) built on Hansen and Prescott (2002) to study the emergence of the social security system along this transition. Kopecky (2011) analyzes the rise in retirement over the course of the 20 th century. In 1880 more than 75 percent of 65 -year-old males were still working, compared with only 20 percent in 2000. Kopecky and Suen (2010) develop a model of a city with two modes of transportation, namely buses and cars, and address the impact of the automobile on suburbanization between 1910 and 1970. The expansion of the American West is addressed in Vandenbroucke (2008), using a model that incorporates endogenous fertility and migration. Last, some of the literature reviewed in Section 29.10 also falls within the category of quantitativetheoretic history; viz., Albanesi and Olivetti (2016), Fernandez-Villaverde et al. (2014), Greenwood and Guner (2009, 2010), Greenwood et al. (2005b), Knowles and Vandenbroucke (2019), and Vandenbroucke (2014).

\subsection{The decline in marriage}

Since the best way to learn about someone else is by being together, intensive search is more effective when unwed couples spend considerable time together, perhaps including trial marriages. Yet when contraceptives are crude and unreliable, trial marriages and other premarital contact greatly raise the risk of pregnancy. The significant increase during this century in the frequency of trial marriages and other premarital contact has been in part a rational response to major improvements in contraceptive techniques, and is not decisive evidence that young people now value sexual experiences more than they did in the past. Gary S. Becker (1991, p. 326)

Since World War II there has been a dramatic increase in the fraction of young women who have never been married and the contemporaneous rise in the age of first marriage. These two trends are shown in Fig. 29.1. (All data sources are provided in Appendix C Data sources.) In 1900 only 40 percent of women in the 18-to-29 age range had never been married. By 2015 this had jumped to 77 percent. The median age of a first marriage rose from 22 to 28 years. The hypothesis entertained here is this: the decline in marriage is due, at least in part, to technological improvements in contraception. As the failure rate for contraception fell, the cost of a sexual relationship for a single woman also declined. This altered the cost/benefit calculation for marrying a partner at hand, favoring the option of postponing marriage until a more suitable partner is found.

Somewhat paradoxically as contraception improved, the number of non-marital births rose. Over the course of the 20th century non-marital births rose continuously, as is displayed by the right panel of Fig. 29.2. This occurred for two reasons: the fraction of never-married women has increased (Fig. 29.1) and never-married women are more sexually active today than in the past (which is discussed below). The left panel shows that non-marital births have increased throughout the postwar period for every age group of adult women. Additionally, non-marital births for women in the adult age groups now exceed those for teenagers.

Never-married women are much more sexually active today than in yesteryear. The percentage of 20-year-old women experiencing premarital sex rose precipitously over the course of the 20th century. Only 8 percent of women born around 1900 had premarital sex before age 20, compared with 76 percent born between 1978 and 88-see Fig. 29.3. Furthermore, the circa 1900 cohort of women had around 2.8 sexual partners before marriage, including their husbands, while the 1959-68 cohort had 7.0 partners. 


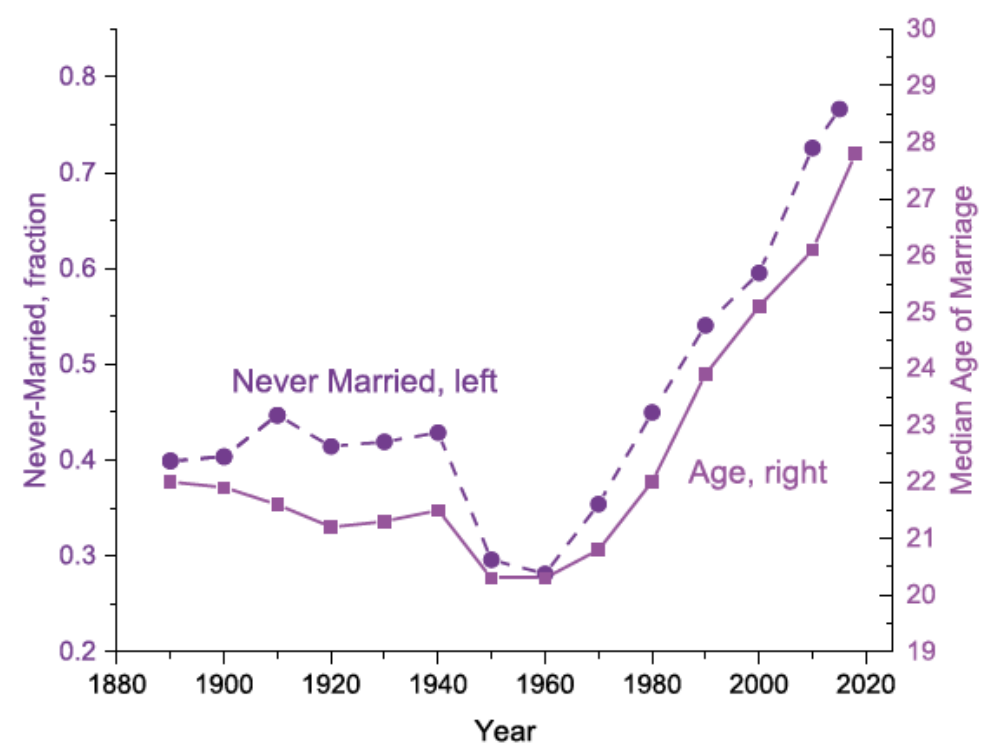

FIGURE 29.1

Marriage in the United States, 1880 to 2015-18. The figure plots the fraction of the female population, ages 18-29, that are never married and the median age of first marriage for women. See Appendix C Data sources for all data sources.

A marital search model is developed to examine, both theoretically and quantitatively, the impact on marriage of technological innovation in contraception. The model is set up in Section 29.4. In particular, each period a single searches for a partner on a marriage market. If the person is matched, they can choose either to have a casual relationship with the partner or enter into marriage. There are two types of casual relationships; viz., sexual and nonsexual ones. A non-marital sexual love affair involves the risk of pregnancy, which depends on the effectiveness of contraception.

When choosing between a casual relationship and marriage a person examines the marriageability of their partner versus the momentary utility from a non-marital romance and then continuing the search for a more marriageable mate. This choice is presented in Section 29.5. To keep things simple, the analysis abstracts from divorce. Likewise, when deciding between either a premarital abstinent or a sexual relationship the individual weighs off the extra utility from having sex against the expected cost of an out-of-wedlock birth. This decision is formalized in Section 29.6. It is established theoretically that an improvement in contraceptive technology leads to: a decline in the rate of marriage (Section 29.5); an increase in the fraction of the population that are never-married (Section 29.7.1); a postponement in the age of marriage (Section 29.7.1); and a rise in the fraction of singles that are sexually active (Section 29.7.2). Out-of-wedlock births may rise or fall with an advance in contraceptive technology (Section 29.7.4).

The theoretical model is subjected to some quantitative analysis in Section 29.8. To begin with, a series measuring the failure rate of contraception is constructed. The odds of a pregnancy for a sexually active woman dropped precipitously between 1900 and 2015-18. The analysis focuses on two periods 


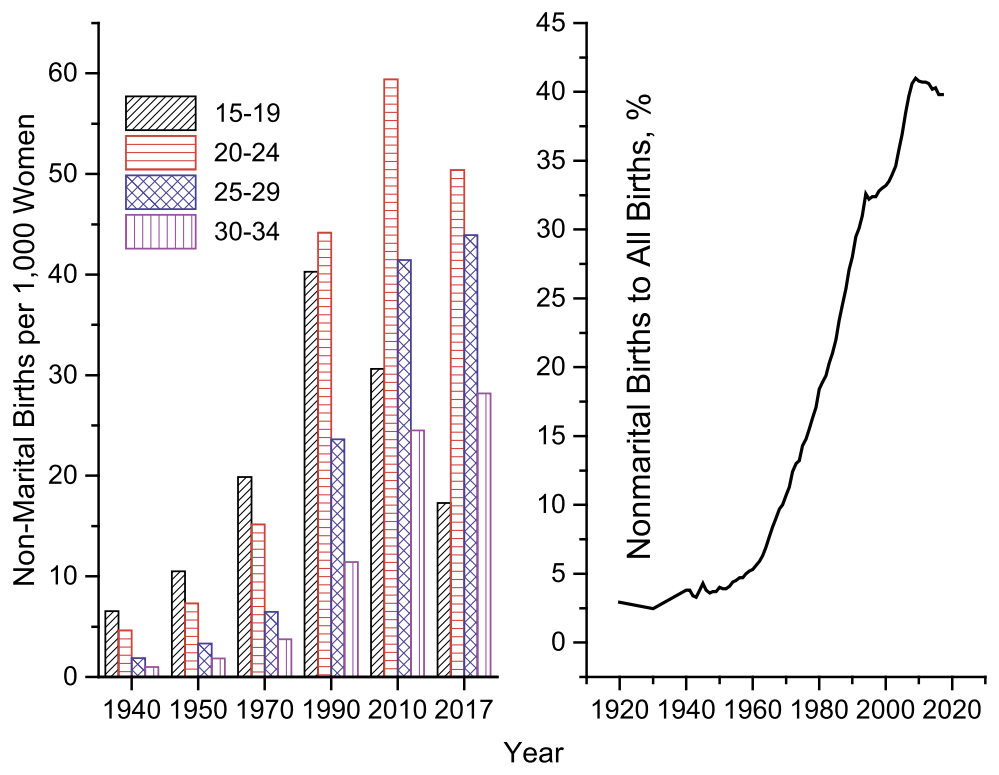

FIGURE 29.2

Non-Marital Births in the United States. The right panel shows non-marital births as a percentage of all births, 1920-2017. The left panel displays non-marital births by age group per 1,000 women at various times in the postwar period.

in U.S. history, 1900 and 2000. The model is calibrated to see if it can match facts from the U.S. data, such as the waning in the fraction of women who have ever been married, and the waxing in the fraction of single women who had premarital sex, out-of-wedlock births, and the number of sexual partners before marriage. The developed framework matches these facts well. The mapping between data targets and parameter values is unpacked by computing the Jacobian for the model.

Last, a review of the relevant economics literature on the decline in marriage is presented in Section 29.10. The discussion now turns to a brief history of contraception.

\subsection{Contraception in the 19th and 20th centuries}

Birth control advanced along two fronts in the 19th and 20th centuries. First, knowledge about contraception began to disseminate. Second, there was improvement in contraceptive technologies. Historically, fertility for married women was controlled in the United States, albeit very imperfectly, using primitive contraception. These technologies would have been too risky to use for unmarried women.

Using a reproductive period of 25 years and an interval between births of 1.5 years, Livi-Bacci (2012) estimates that a reasonable upper bound on the number of children that a woman can have is 16.7. No society has approached this theoretical maximal rate of reproduction. The closest examples are the 17th century Québécois and the interwar Canadian Hutterites with total fertility rates of 11.4 


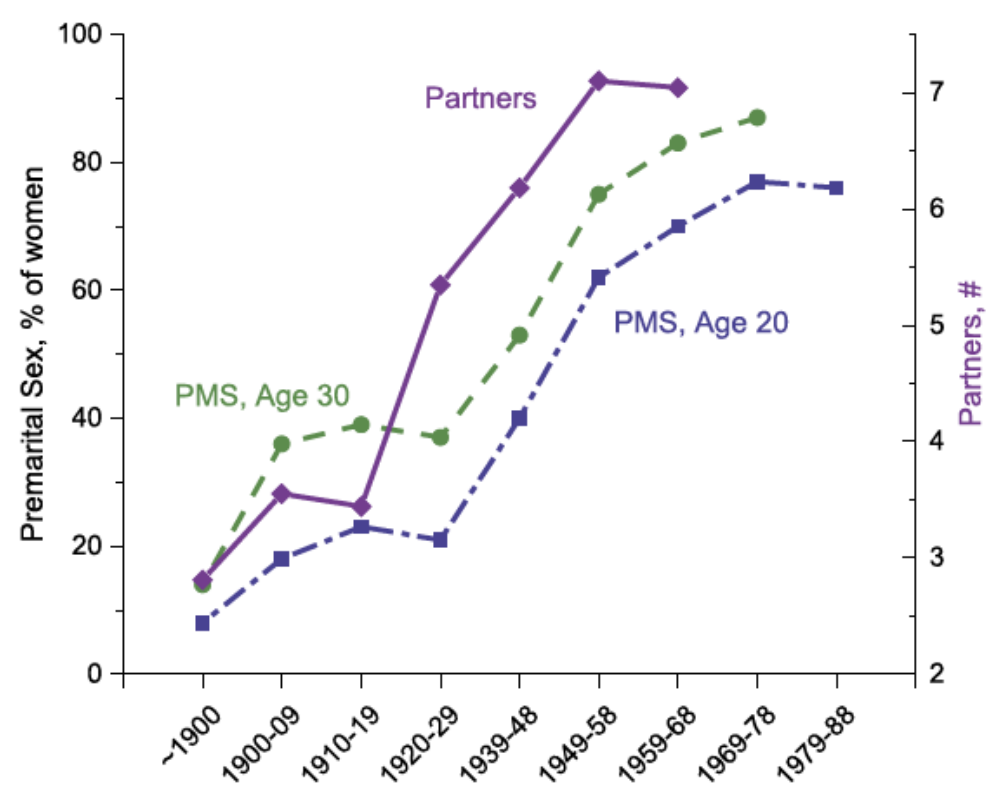

FIGURE 29.3

Premarital Sex in 20th-Century America. The graph plots the percentage of women, by various cohorts, who had premarital sex by ages 20 and 30, left axis. It also charts the number of partners these women had before marriage, right axis.

and 9, respectively. ${ }^{3}$ The total fertility rate for white women in the United States fell from 7.1 children in 1800 to just 1.9 kids in 2015 , as can be seen from the right panel of Fig. 29.4. The figure also plots the complementary cumulative distribution functions over births for four cohorts of married women in the United States before the baby boom-see the left panel. First, as can be seen, the distribution of births is well within the biological maximum. Second, the distribution functions are stochastically decreasing with the year of the cohort. That is, as time progresses a woman was less likely to have a large number of births. For example, the first group of bars shows that 15 percent of women born between 1835 and 1839 had 10 or more births. This had dropped to just 1.7 percent for the 1905-09 cohort. At the other end of the spectrum, it can be deduced from the difference in the heights between the fifth and sixth groups of bars that just 7.7 percent of women in the 1835-39 had no children, while 21 percent did for those born between 1905 and 1909. The mean number of births declines with the women's birth years. The mean of 2.5 for the 1905-09 cohort compares with a total fertility rate of 1.9 in 2015. The 1905-09 cohort would have been in their fifties by the time the pill was invented. So, the graph clearly illustrates that somehow family size was limited well before the advent of modern contraception. Historically, family size was limited by abortion, abstinence enforced by the prohibition and

3 Galor and Klemp (2019), in their study of the fecundity of early French Canadian women, relay that one woman had 22 offspring. 

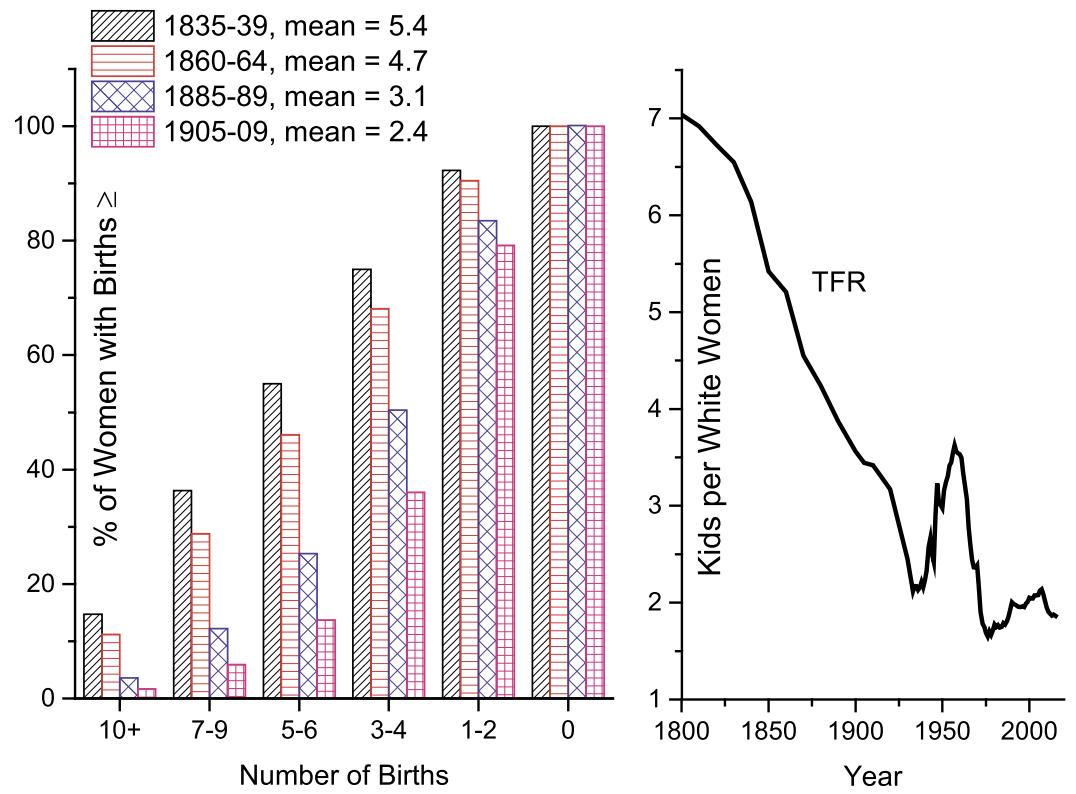

\section{FIGURE 29.4}

Fertility in the United States. The right panel shows the drop in the total fertility rate for white women from 1800 to 2015. Complementary cumulative distribution functions over children ever born for four cohorts of ever-married women are plotted in the left panel. As such, the vertical axis presents the percentage of women who had a number of births greater than or equal to that indicated on the horizontal axis.

stigmatization of premarital sex, crude contraception, child abandonment and infanticide, and delaying the age of marriage (which was important in light of short lifespans).

\subsubsection{Dissemination of information}

In 1823 Francis Place, an English social reformer, circulated a pamphlet in London titled To the Married of Both Sexes of the Working People. In it he wrote [Himes (1936, pp. 216-217)]

"What is done by other people is this. A piece of soft sponge is tied by a bobbin or penny ribbon, and inserted just before the sexual intercourse takes place, and is withdrawn again as soon as it has taken place. Many tie a piece of sponge to each end of the ribbon, and they take care not to use the same sponge again until it has been washed."

An early 19th century sponge is shown in the right panel of Fig. 29.5.

In America, Dr. Charles Knowlton (1832) recommended douching in a pamphlet titled The Fruits of Philosophy (Chapter III on "Promoting and Checking Conception"), writing

"It consists in syringing the vagina immediately after connection with a solution of sulphate of zinc, of alum, pearl-ash, or any salt that acts chemically on the semen, and at the same time produces no unfavorable effect on the female." 


\section{Chapter 29 The wife's protector}
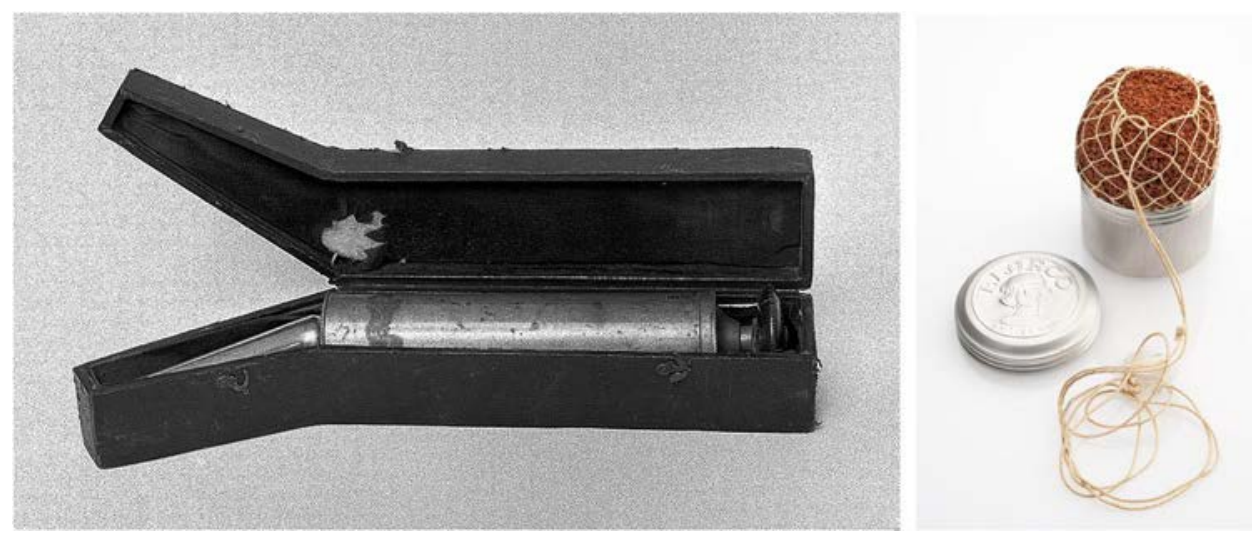

\section{FIGURE 29.5}

A 19th century pewter vaginal syringe with its case is displayed in the left panel. The right panel shows a rubber sponge, in its original box (circa 1901-1930). Sponges were widely used as contraception in the early 1900s. Sponges were often soaked in spermicidal agents, of varying effectiveness. In a 1914 pamphlet Family Limitation, Margaret Sanger relayed that absorbing boric acid into the sponge yielded "satisfactory results." Sources: wellcomecollection.org and Science Museum, London.

The first edition was published anonymously, given the puritanical beliefs of the time. For trying to distribute his book, Knowlton was imprisoned for three months. Fig. 29.5, left panel, shows an early vaginal syringe used for douching. Last in Moral Physiology; or, A Brief and Plain Treatise on the Population Question (Chapter VI) Robert Dale Owen (1842) advocated withdrawal, stating

"Among the modes of preventing conception which may have prevailed in various countries, that which has been adopted, and is now practised by the cultivated classes on the continent of Europe, by the French, the Italians, and, I believe, by the Germans and Spaniards, consists of complete withdrawal, on the part of the man, immediately previous to emission. This is, in all cases, effectual."

The dissemination of knowledge about birth control picked up dramatically at the start of the 20th century. In 1916 Margaret Sanger opened the first birth control clinic in America. Some 400 women received instruction about contraception before the clinic was closed by the police nine days later. Sanger served a thirty day jail sentence in 1917 for opening the clinic. Following a 1918 ruling by the New York State Court of Appeals in The People of the State of New York v. Margaret H. Sanger, which allowed contraception to be distributed by physicians, she opened the first continuously operational birth control clinic in 1923. The clinic was staffed by female physicians and counselors. In London, England, Mary Stopes did much the same thing, opening in 1921 the first birth control clinic in the British Empire. The first medical book in America aimed at providing physicians with up-todate scientific information about contraception was the Technique of Contraception: The Principle and Practice of Anti-Conceptional Methods, written by Dr. James F. Cooper in 1928. A table in the book (p. 221) gave failures rates for condoms, douching, cervical stems, spermicides, withdrawal, etc. The book was dedicated to Margaret Sanger. 

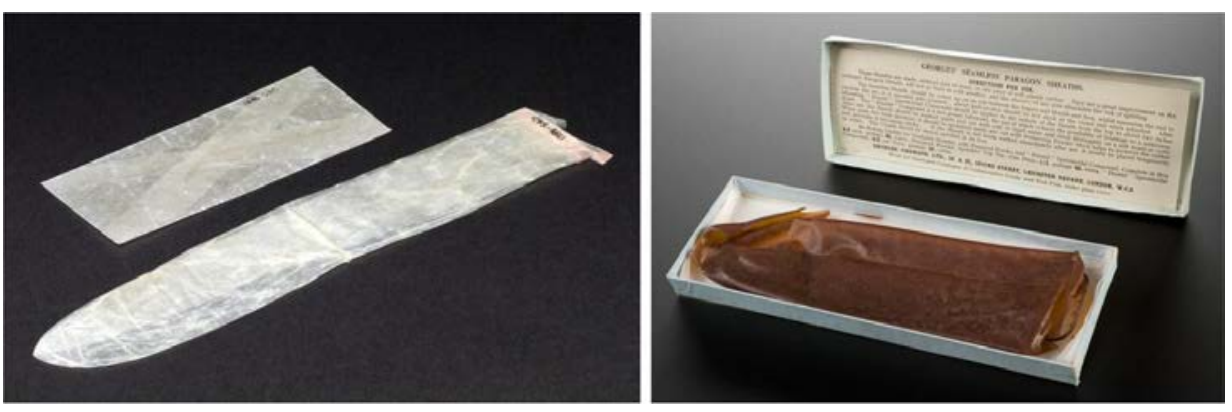

\section{FIGURE 29.6}

The left panel shows a European condom, made from animal gut, in a waxed paper envelope (circa 1801-1850). The right panel pictures a re-usable English rubber condom in its original box, complete with instructions (circa 1948). Source: Science Museum, London.

\subsubsection{Technological advance}

There also was considerable technological advance in contraception over this period. Start with the condom. Fig. 29.6 shows two early versions. In 1844 The United States Practical Receipt Book (p. 87) provided instructions on how to make a condom:

"Take the caecum of the sheep; soak it first in water, turn it on both sides, then repeat the operation in a weak ley of soda, which must be changed every four or five hours for five or six successive times; then remove the mucus membrane with the nail; sulphur, wash in clean water, and then in soap and water; rinse, inflate, and dry. Next cut it to the required length and attach a piece of ribbon to the open end. Used to prevent infection or pregnancy. The different qualities consist of extra pains being taken in the above process, and in polishing, scenting, \&c."

Packages of a dozen rubber condoms were selling in 1890 for 50 cents. At the time a tradesman would have earned an hourly wage of 20 cents, so this translates into a time price of 2.5 hours of work. Quality control was an issue; however, giving condoms a bad name. According to Tietze (1963), a study conducted in 1934-1935 found the following distribution over defects: burst, 29.4 percent; holes, 15.2 percent; flaws, 14.5 percent; total, 59.1 percent. This led to the U.S. Food and Drug Administration controlling quality standards. Also, Dr. Cooper in his 1928 medical book noted another disadvantage: "Blunting of sensation. Frequent refusal by male." The quality of condoms had increased dramatically by the 1960s, making them one of the most effective forms of contraception.

In 1846 the United States Patent Office granted patent number 4,729. The introduction to the patent specification read:

"Be it known that I, John B. Beers, of the city of Rochester, in the county of Monroe and State of New York,

have invented a new Instrument called the 'wife's protector,' the design of which is to Prevent conception."

The drawing that was submitted with his patent application is shown in Fig. 29.7. The specification of Beers's letters patent is provided in Appendix A Beers. His Wife's Protector instrument, a simple diaphragm-like device, inserted a hoop covered by an oil-silk membrane that prevented semen from entering the uterus. An interesting feature of the patent specification is that it explicitly stated that it was intended to prevent pregnancy, a risky venture at the time. Cervical caps and diaphragms also were 

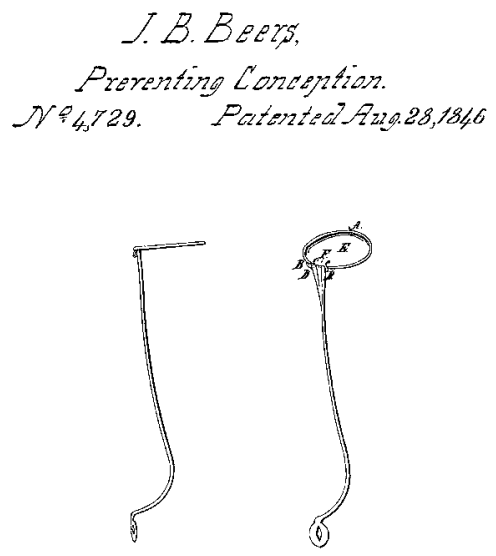

\section{FIGURE 29.7}

The drawing that was submitted with John B. Beers's 1846 patent application for his Wife's Protector contraceptive device. Source: United States Patent and Trademark Office.

introduced in the 1800s. The left panel of Fig. 29.8 shows a late 19th century German pessary. The pessary was an intracervical device (IUC). It worked after conception by provoking a foreign inflammatory reaction that stops a newly fertilized embryo from implanting and growing in the lining of the uterus.

There was also technological improvement in spermicides, used with or without other contraceptives such as condoms, diaphragms, sponges, etc. An English pharmacist introduced in 1885 a suppository made out of cocoa butter and quinine sulfate. Others at the time combined cocoa butter, which melted at a low temperature, with boric acid, tannic acid, or bichloride of mercury. In 1937 phenylmercuric acetate was introduced in a product called Volper. This was a highly effective spermicide, but was subsequently banned in the United States because of concerns about mercury. In the 1950s surface active agents (surfactants) were introduced. These are non-irritating. On this, in the past many products were used as spermicides. For example, Sanger (1914) mentions Lysol in Family Limitation and Belsky (1975) relays that Coca-Cola was used in India.

In the 1920s German gynecologist Ernst Grafenberg developed the intrauterine device (IUD), displayed in the right panel of Fig. 29.8. Both the pessary and this early IUD were infection prone. And it should be noted that pelvic infections could only be dealt with easily after the introduction of antibiotics in the 1940s. Fast forwarding to 1967, Howard Tatum and Jamie Zipper developed the first copper-bearing IUD. It was T shaped and made of inert plastics, which made it fit better and less vulnerable to infection. Zipper had shown that copper reduced the risk of pregnancy in rabbits. Interestingly, Grafenberg's IUD also contained copper, but its effect on preventing pregnancy went unnoticed.

Also in the 1920s and 1930s two gynecologists, Kyusaku Ogino and Hermann Knaus, provided an accurate tracking of the ovulation cycle. This provided a scientific basis for the rhythm method. As a result inexpensive devices were marketed, such as the Rythmeter, which calculated the time of ovulation and the periods of fertility and infertility. The rhythm method evolved into more modern 

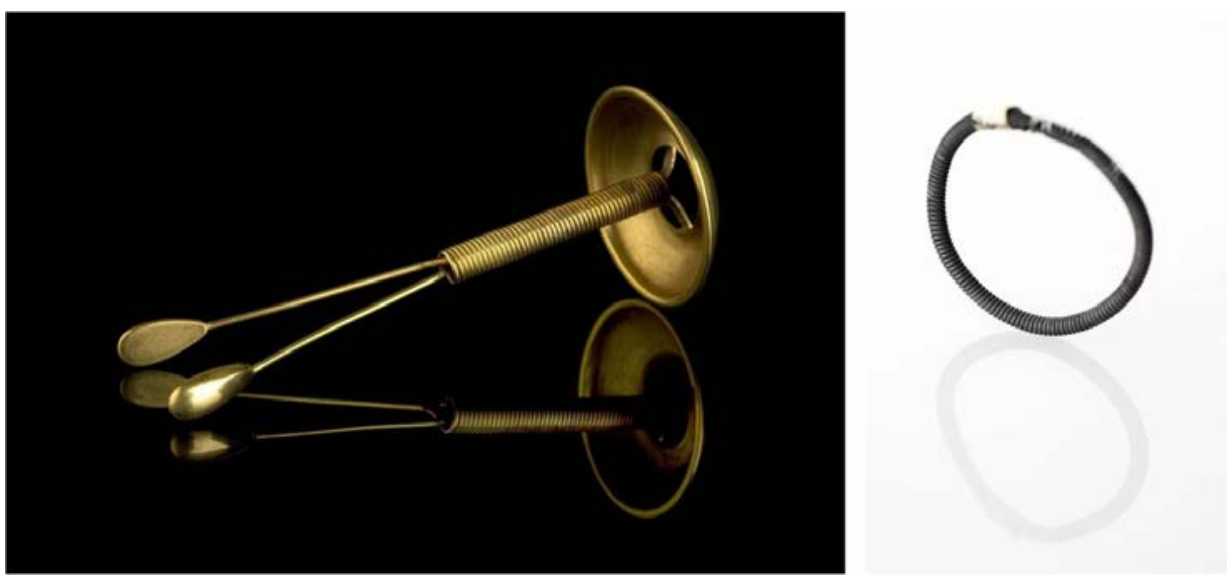

\section{FIGURE 29.8}

A gold wishbone stem pessary is pictured in the left panel. It was developed around 1880 in Germany. The right side panel shows a Grafenberg IUD, circa 1920s. Source: Science Museum, London.

ones, such as Sympto-Thermal Method of the late 1970s, which combines the rhythm calendar with changes in body temperature and cervical mucus.

The pill symbolizes technological improvement in contraception. It synthesizes two hormones, estrogen and progestin, in order to prevent ovulation. Scientists discovered and isolated hormones in the 1930s. Manufacturing them was expensive and slow, though. Russell Marker developed an efficient method for doing so in the 1950s. Around that time Carl Djerassi synthesized a progestin that could be taken orally. Capitalizing on these earlier breakthroughs, biologists Min Chueh Chang and Gregory Pincus teamed together with obstetrician John Rock to develop the pill, which was approved by the FDA in 1960. Today transdermal patches, implants, and injections can be used to deliver estrogen and progestin.

\subsection{Setup}

Each period a new cohort of adult singles enters the economy. The initial size of a cohort is one, with a per-period survival rate for a person of $\sigma$. The analysis focuses on steady states. Given this, the time-invariant size of the population is $1 /(1-\sigma)$.

Imagine the problem facing a single. This single will meet a partner in the current period with probability $\mu$. If a meeting occurs, the person can decide to have either a marital or non-marital relationship with their partner. There are two types of non-marital love affairs: sexual and nonsexual ones. An abstinent romantic entanglement yields a momentary utility level of $a \geq 0$. A sexual liaison results in a current utility level of $l>a$. Libido, $l$, for the current love affair is drawn from the cumulative distribution function $L(l)$, with associated density function $L_{1}(l)$. The value of $l$ is known at the time of deciding between either an abstinent or sexual relationship. A non-marital sexual relationship may 


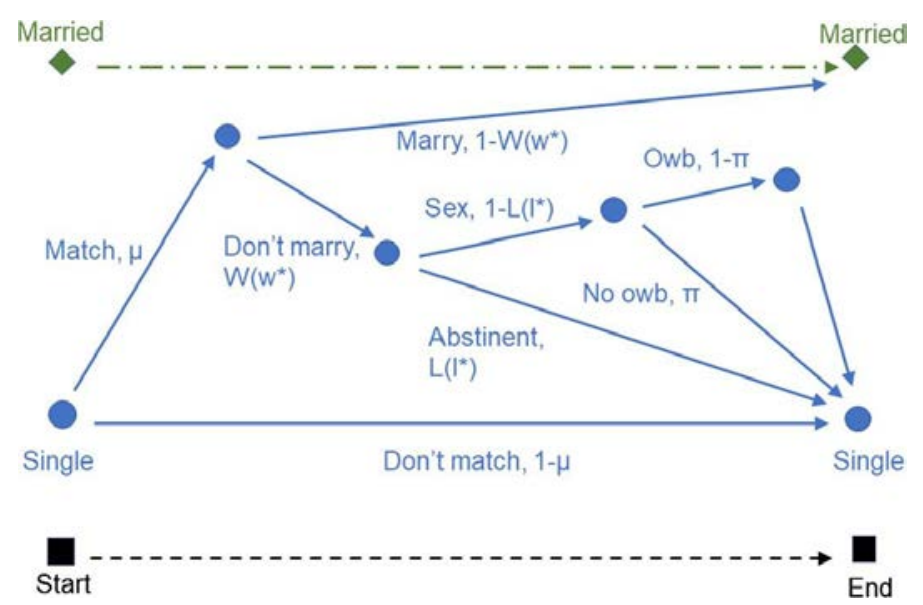

\section{FIGURE 29.9}

Timing of Events. The diagram shows the timing of events within a period. The circles denote nodes when an individual is single, whereas the diamonds represent nodes when they are married. A single matches with probability $\mu$. If matched, they remain single with probability $W\left(w^{*}\right)$, have sex with odds $1-L\left(l^{*}\right)$, and have an out-of-wedlock birth (owb) with probability, $1-\pi$. The determination of $w^{*}$ and $l^{*}$ is discussed in the next two sections.

result in an out-of-wedlock birth. With probability $\pi$ the person avoids a pregnancy, while with probability $1-\pi$ they do not. Let an out-of-wedlock birth have a utility cost of $O$. Finally, if the person marries, then they get the random lifetime utility $w$. The value of being wed, $w \geq 0$, is drawn from the cumulative distribution function $W(w)$, with associated density function $W_{1}(w)$. The value of $w$ is known at the time of the marriage decision, but the level of joy, $l$, from a casual sexual endeavour is not. Marriage is an absorbing state. People discount the future at rate $\beta$, which incorporates the survival rate of $\sigma$. Fig. 29.9 illustrates the timing of events in the model.

\subsection{Married or single life?}

The key step in the analysis is formulating the recursion that defines the expected lifetime utility of being single in the current period, $S$. Suppose that the person is single in the current period. With probability $1-\mu$ the person remains unmatched. In this case, they realize no current utility. Since they enter next period as unmarried, the discounted expected utility for an unmatched single is $\beta S$. With probability $\mu$ they meet someone. If so, the single can choose either to marry or remain single. On the one hand, married life yields the lifetime utility $w$. On the other hand, let the expected momentary utility for a matched single be $N(\pi)$, which is increasing in the odds of safe sex $\pi$. The function $N(\pi)$ is unpacked in the next section. The matched single will enter next period still single, which has the discounted continuation value of $\beta S$. Hence, the expected lifetime utility for a matched single is $N(\pi)+\beta S$. Clearly, a matched single will choose the option that yields the highest level of expected 
lifetime utility. The decision to marry in the current period can be cast as

$$
\begin{array}{lll}
\text { Marry, } & \text { if } & w \geq N(\pi)+\beta S ; \\
\text { Remain Single, } & \text { if } & w<N(\pi)+\beta S,
\end{array}
$$

where recall that the marriage decision is made after the value for $w$ is realized. There will exist a threshold rule for $w$, denoted by $w^{*}$, such that

$$
\begin{array}{ll}
\text { MARRY, } & \text { if } \quad w \geq w^{*} ; \\
\text { REMAIN SINGLE, } & \text { if } \quad w<w^{*},
\end{array}
$$

where $w^{*}$ is given by

$$
w^{*}=N(\pi)+\beta S .
$$

It is now easy to see that $S$ satisfies the recursion

$$
S=\underbrace{(1-\mu) \beta S}_{\text {unmatched }}+\underbrace{\mu E[\max \{N(\pi)+\beta S, w\}]}_{\text {matched }} .
$$

The above recursion can be rewritten as

$$
S=(1-\mu) \beta S+\mu\{W\left(w^{*}\right) \underbrace{[N(\pi)+\beta S]}_{w^{*}}+\int_{w^{*}} w d W(w)\},
$$

which implies

$$
S=\frac{\mu W\left(w^{*}\right) w^{*}+\mu \int_{w^{*}} w d W(w)}{1-(1-\mu) \beta} .
$$

Therefore, by substituting (29.2) into (29.1), it follows that at the threshold

$$
w^{*}=N(\pi)+\beta \mu\left[\frac{W\left(w^{*}\right) w^{*}+\int_{w^{*}} w d W(w)}{1-(1-\mu) \beta}\right] .
$$

So how does contraception affect marriage? To see this, totally differentiate the above equation with respect to $\pi$ and $w^{*}$ to get

$$
\frac{d w^{*}}{d \pi}=\frac{N_{1}(\pi)}{1-\beta \mu W\left(w^{*}\right) /[1-(1-\mu) \beta]}>0 .
$$

In obtaining and signing this expression three facts are worth noting. First, the expected momentary utility for a matched single is increasing in the odds of safe sex, $\pi$, implying $N_{1}(\pi)>$ $0-$ Proposition 29.3 in the next section establishes this. Second, at the threshold $d \beta\left[\mu W\left(w^{*}\right) w^{*}+\right.$ $\left.\mu \int_{w^{*}} w d W(w)\right] / d w^{*}=\beta \mu W\left(w^{*}\right)$. Third,

$$
1-\beta \mu W\left(w^{*}\right) /[1-(1-\mu) \beta]=\left(1-\beta\left\{1-\mu\left[1-W\left(w^{*}\right)\right]\right\}\right) /[1-(1-\mu) \beta]>0 .
$$




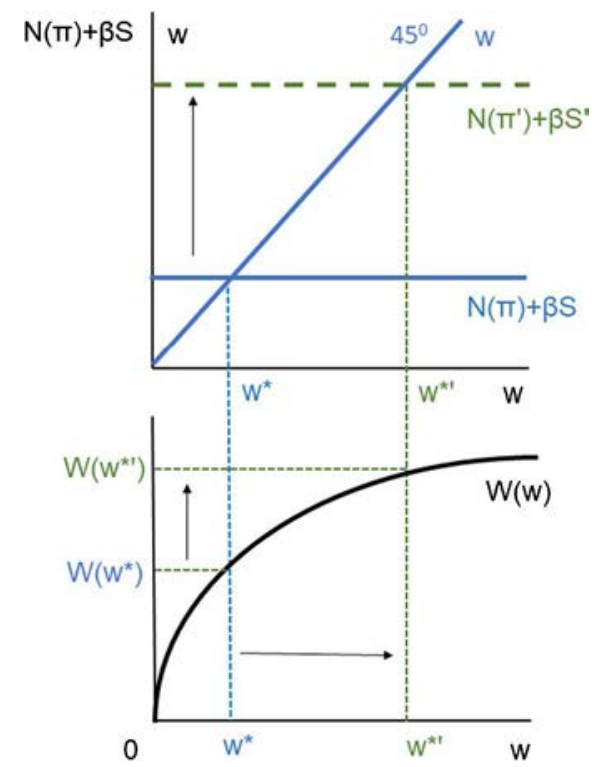

\section{FIGURE 29.10}

The determination of $w^{*}$ and $W\left(w^{*}\right)$. The threshold for marriage, $w^{*}$, is determined where the $N(\pi)+\beta S$ and $w$ lines intersect, as the top panel illustrates. To the left of $w^{*}$ a person will choose single life, because the $N(\pi)+\beta S$ curve lies above the $w$ one. To the right the opposite happens. An increase in the effectiveness of contraception, $\pi$, results in the $N(\pi)+\beta S$ curve shifting up to $N\left(\pi^{\prime}\right)+\beta S^{\prime}$. As a consequence the threshold for marriage moves higher or rightward from $w^{*}$ to $w^{* \prime}$. The fraction of matched singles choosing not to marry then rises from $W\left(w^{*}\right)$ to $W\left(w^{* \prime}\right)$, as the bottom panel shows.

Intuitively speaking, when contraception becomes more effective there is a hike in the expected momentary utility for a matched single, $N(\pi)$. As a result, matched singles become choosier about who they will marry and the threshold value of love that has to be met for a marriage, $w^{*}$, moves up. The situation is portrayed in Fig. 29.10. For a matched individual the value of marriage is just $w$. This is shown by the $45^{0}$ degree line marked $w$. The expected lifetime utility for a person who is currently single is shown by the line labeled $N(\pi)+\beta S$. This line is not a function of the realized value for $w$, as can be seen by inspecting Eq. (29.2). The threshold value for $w$, or $w^{*}$, at which the individual is indifferent between marriage and single life occurs where the $w$ and $N(\pi)+\beta S$ lines intersect. Suppose that contraception improves; in other words, let $\pi$ rise. The expected value of single life moves up, as shown by the shift in the curve from $N(\pi)+\beta S$ to $N\left(\pi^{\prime}\right)+\beta S^{\prime}$. The fact that $S^{\prime}>S$ is shown below. The $w$ curve does not shift, since the random draw for married life is not a function of $\pi$. As a result, the threshold value for marriage, $w^{*}$, increases from $w^{*}$ to $w^{* \prime}$. This causes the fraction of matched singles who choose not to marry to rise from $W\left(w^{*}\right)$ to $W\left(w^{* \prime}\right)$. The above analysis is summarized by the proposition below.

Proposition 29.1 (Marriage Rate). An improvement in contraception, or an increase in $\pi$, leads to a decline in the marriage rate, $1-W\left(w^{*}\right)$, propelled by an increase in $w^{*}$. 
Interestingly, the expected lifetime utilities for both married and single lives, $\left\{1 /\left[1-W\left(w^{*}\right)\right]\right\} \times$ $\int_{w^{*}} w d W(w)$ and $S$, increase. For married life, it is straightforward to calculate that

$$
\frac{d\left(\left\{1 /\left[1-W\left(w^{*}\right)\right]\right\} \int_{w^{*}} w d W(w)\right)}{d \pi}=\frac{1}{1-W\left(w^{*}\right)}\left[\frac{1}{1-W\left(w^{*}\right)} \int_{w^{*}} w d W(w)-w^{*}\right] W_{1}\left(w^{*}\right) \frac{d w^{*}}{d \pi}>0,
$$

where the term in brackets on the righthand side is greater than 0 . The expected lifetime value of married life rises because the expected value of single life has improved. This allows singles to be pickier about their marriage partner. For single life, it follows from Eq. (29.2) that

$$
\frac{d S}{d \pi}=\frac{\mu W\left(w^{*}\right)}{1-(1-\mu) \beta} \frac{d w^{*}}{d \pi}>0
$$

This justifies the upward shift of the $N(\pi)+S$ curve, following an increase in $\pi$, that is shown in Fig. 29.10-by assumption $N(\pi)$ is increasing in $\pi$. Single life improves because there is a boost in the expected momentary utility for a matched single, $N(\pi)$, due to the fact that premarital sex is now safer.

\subsection{An abstinent or sexual non-marital relationship?}

Consider the decision facing a matched single who has decided not to marry. An abstinent relationship yields a momentary utility value of $a$, while for a sexual one it depends on libido, $l$. At the time of making this decision the person knows the value of $l$. On the one hand, a sexual endeavour leads to the thrill $l$. On the other hand, the person may become pregnant with probability $1-\pi$ and suffer the cost of an out-of-wedlock birth, $O$. Therefore, the expected momentary utility from a sexual relationship is $l-(1-\pi) O$.

The momentary utility for a matched single who has decided not to marry and subsequently drawn a value for $l$ is given by

$$
\max \{a, l-(1-\pi) O\}
$$

Hence, the decision to have a non-marital sexual relationship is described by

$$
\begin{array}{ll}
\text { Abstinent, } & l \leq a+(1-\pi) O ; \\
\text { SexuAl RELATIONSHip, } & l>a+(1-\pi) O .
\end{array}
$$

There will exist a threshold rule for $l$, denoted by $l^{*}$, such that

$$
\begin{array}{ll}
\text { Abstinent, } & \text { if } l \leq l^{*} ; \\
\text { Sexual Relationship, } & \text { if } l>l^{*},
\end{array}
$$

where $l^{*}$ is given by

$$
l^{*}=a+(1-\pi) O .
$$

Therefore, the odds of abstinent and sexual relationships, contingent on being matched, are $L\left(l^{*}\right)$ and $1-L\left(l^{*}\right)$. The fraction of singles having premarital sex is then $\mu\left[1-L\left(l^{*}\right)\right]$. As the efficacy 


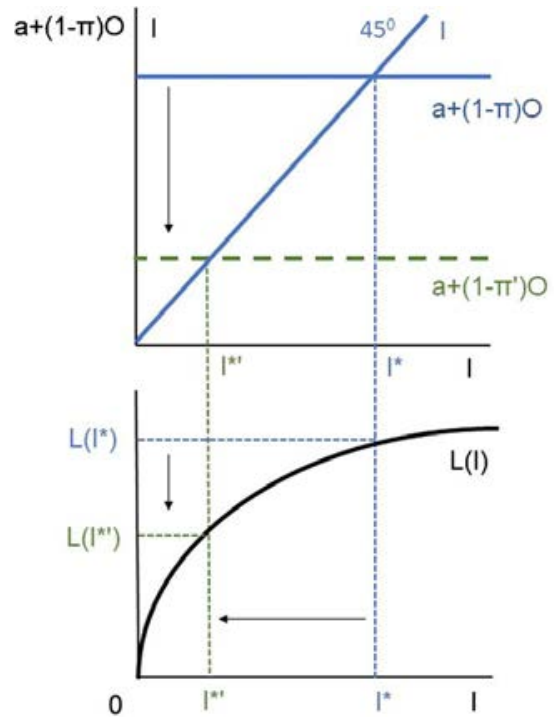

\section{FIGURE 29.11}

The determination of $l^{*}$ and $L\left(l^{*}\right)$. The threshold level of libido, $l^{*}$, occurs where the $l$ and $a+(1-\pi) O$ lines in the upper panel intersect. An increase in $\pi$ lowers the cost of premarital sex, so that $a+(1-\pi) O$ shifts down to $a+\left(1-\pi^{\prime}\right) O$. As a result, $l^{*}$ drops to $l^{* \prime}$. The odds of abstinence for a matched single fall, consequently, from $L\left(l^{*}\right)$ to $L\left(l^{* \prime}\right)$, as shown by the lower panel.

of contraception, $\pi$, improves, the probability of an out-of-wedlock birth for a sexually active single drops. So, the expected cost, $(1-\pi) O$, of being sexually active declines. As a result, there will be more sexually active singles. Fig. 29.11 illustrates the situation. The $45^{0}$ line marked $l$ in the upper panel is the benefit from premarital sex. The horizontal line labeled $a+(1-\pi) O$ represents its cost. This has two components; namely, the forgone value of abstinence, $a$, and the expected cost of an outof-wedlock birth, $(1-\pi) O$. The threshold level of libido, $l^{*}$, is determined in the upper panel where the $l$ and $a+(1-\pi) O$ lines intersect or where the cost and benefit of premarital sex are equalized. The lower panel plots the cumulative distribution function $L(l)$. As such, it gives the odds of abstinence, $L\left(l^{*}\right)$, conditional on a match. When contraception improves, the cost of premarital sex falls so that the $a+(1-\pi) O$ line moves down to $a+\left(1-\pi^{\prime}\right) O$, which results in $l^{*}$ dropping to $l^{* \prime}$. The fraction of matched singles that pick abstinence declines from $L\left(l^{*}\right)$ to $L\left(l^{* \prime}\right)$.

Proposition 29.2 (Sexually Active Singles). The fraction of singles in a sexual relationship, $\mu[1-$ $L\left(l^{*}\right)$, is increasing in the odds of safe sex, $\pi$.

Proof. It's easy to see that

$$
\mu \frac{1-d L\left(l^{*}\right)}{d \pi}=\mu L_{1}\left(l^{*}\right) O>0[\operatorname{using}(29.3)]
$$


The expected momentary utility of not marrying for a matched single is

$$
N(\pi)=L\left(l^{*}\right) a+\int_{l^{*}} l d L(l)-\left[1-L\left(l^{*}\right)\right](1-\pi) O .
$$

The level of expected utility for a matched single improves with technological progress in contraception for two reasons. First, for a sexually active single the odds of an out-of-wedlock birth have declined. Second, a single is more likely to be sexually active, since $1-L\left(l^{*}\right)$ rises, and having sex yields a higher level of expected utility than abstinence because $\int_{l^{*}} l d L(l)-(1-\pi) O>a$.

Proposition 29.3 (Current Utility for a Matched Single). The level of current expected utility for a matched single, $N(\pi)$, is increasing in the odds of safe sex, $\pi$; i.e., $N_{1}(\pi)>0$.

Proof. Differentiating (29.4) with respect to $\pi$ yields

$$
N_{1}(\pi)=L_{1}\left(l^{*}\right) O\left[-a+l^{*}-(1-\pi) O\right]+\left[1-L\left(l^{*}\right)\right] O
$$

$$
=\left[1-L\left(l^{*}\right)\right] O>0,
$$

where use is made of the facts that $d L\left(l^{*}\right) / d \pi=-L_{1}\left(l^{*}\right) O$ and $l^{*}=a+(1-\pi) O$. Therefore, the momentary expected utility value for a matched single rises with the odds of safe sex, $\pi$.

\subsection{Statistical mechanics}

\subsubsection{Marriage by age}

How many people will be married by a given age in the population? Recall that each period a cohort of new adult singles enters the economy. This cohort initially has unit mass but its size atrophies over time according to the survival rate $\sigma$. Follow this cohort as it ages period by period. Suppose that at the end of period $j-1$ there are $s_{j-1}$ singles around from the cohort. Then, there will be $\sigma s_{j-1}$ singles around at the beginning of period $j$. Out of this, $\mu \sigma s_{j-1}$ people match implying that the number of new marriages is

$$
n_{j} \equiv \mu\left[1-W\left(w^{*}\right)\right] \sigma s_{j-1}, \text { where } s_{0} \equiv 1 / \sigma .
$$

The number of singles in the cohort then evolves according to

$$
s_{j}=\sigma s_{j-1}-n_{j}=\left[1-\mu+\mu W\left(w^{*}\right)\right]^{j} \sigma^{j-1} .
$$

The term on the right is easy to explain. If a person enters a period single, then the odds of them exiting the period single are given by $1-\mu+\mu W\left(w^{*}\right)$. On this, the probability of not matching is $1-\mu$, while the probability of matching and not marrying is $\mu W\left(w^{*}\right)$. So, the odds of not marrying at the end of $j$ periods are $\left[1-\mu+\mu W\left(w^{*}\right)\right]^{j}$ while the chance of surviving this long is $\sigma^{j-1}$. To summarize, the cohort evolves in the manner displayed in Table 29.1.

The impact of contraception on the married and never-married populations can now be analyzed. The fraction of the age- $j$ population that is never married is

$$
\frac{s_{j}}{\sigma^{j-1}}
$$




\begin{tabular}{|c|c|c|c|c|}
\hline \multicolumn{5}{|c|}{$\begin{array}{l}\text { Table } 29.1 \text { The evolution of a cohort by age. Each period a new cohort of unit mass } \\
\text { enters the economy. The table gives the fractions by age of the original cohort that } \\
\text { are newly married, single, married, and surviving. In a steady state the total size of } \\
\text { the population is } 1 /(1-\sigma) \text {. An entry in a cell also represents number of people in } \\
\text { the population in the designated situation. To get the fraction of the population in } \\
\text { this case just divide by } 1 /(1-\sigma) \text {. }\end{array}$} \\
\hline \multicolumn{5}{|c|}{ Marriage Statistics for a Cohort by Age } \\
\hline Age & Newly Married, $n$ & Remaining Single, $s$ & Total Married, $m$ & Surviving \\
\hline 1 & $n_{1}=\mu\left[1-W\left(w^{*}\right)\right]$ & $s_{1}=1-\mu+\mu W\left(w^{*}\right)$ & & 1 \\
\hline 2 & $n_{2}=\mu\left[1-W\left(w^{*}\right)\right] \sigma s_{1}$ & $s_{2}=\left[1-\mu+\mu W\left(w^{*}\right)\right]^{2} \sigma$ & $m_{2}=\sigma m_{1}+n_{2}$ & $\sigma$ \\
\hline & & & & \\
\hline & $n_{j}=\mu\left[1-W\left(w^{*}\right)\right] \sigma s_{j-1}$ & $s_{j}=\left[1-\mu+\mu W\left(w^{*}\right)\right]^{j} \sigma^{j-1}$ & $m_{j}=\sigma m_{j-1}+n_{j}$ & $\sigma^{j-1}$ \\
\hline
\end{tabular}

while the portion of the population up to and including age $j$ that is never married is

$$
\frac{\sum_{i=1}^{j} s_{i}}{\sum_{i=1}^{j} \sigma^{i-1}}
$$

Now suppose that the odds of safe sex, $\pi$, improve due to technological progress in contraception. From Proposition 29.3 single life becomes more enjoyable. Therefore, a matched single will become pickier about who they marry; that is, $w^{*}$ rises from Proposition 29.1. The fraction of never-married individuals in the population at large moves up, as a consequence.

Proposition 29.4 (Never-Married Population). The fraction of the population that is never married, as defined by (29.5), is increasing in the efficacy of contraception, $\pi$.

Proof. Using the fact that $s_{j}=\left[1-\mu+\mu W\left(w^{*}\right)\right]^{j} \sigma^{j-1}$, it is immediate that

$$
\frac{d s_{j}}{d \pi}=j\left[1-\mu+\mu W\left(w^{*}\right)\right]^{j-1} \sigma^{j-1} \mu W_{1}\left(w^{*}\right) \frac{d w^{*}}{d \pi}>0,
$$

where the sign follows from Proposition 29.1.

The average age of marriage for the age- $j$ population is

$$
\frac{\sum_{i=1}^{j} i n_{i}}{\sum_{i=1}^{j} n_{i}}
$$

One may conjecture that an increase in the efficacy of contraception will postpone the mean age of marriage because the rate of marriage at any age drops by Proposition 29.1. This is true, but the reasoning is not straightforward because the number of the age- $i$ newly married in the population, $n_{i}$, decreases in both the numerator and denominator of (29.6).

Proposition 29.5 (Mean and Median Ages of Marriage). The mean and median ages of marriage are increasing in the efficacy of contraception, $\pi$.

Proof. See Appendix B Theory. 


\subsubsection{Premarital sex}

Let $v_{j-1}$ represent the size of the age- $(j-1)$ population that has never had sex. The size of the age- $j$ populace that hasn't had sex is given by $v_{j}=\left[1-\mu+\mu W\left(w^{*}\right) L\left(l^{*}\right)\right] \sigma v_{j-1}$, where $v_{0} \equiv 1 / \sigma$. To understand this expression, first note that only $\sigma v_{j-1}$ of the original age- $(j-1)$ virgin population will survive until age $j$. Second, out of this the fraction $1-\mu$ will remain unmatched. The proportion $\mu$ will match, but from this segment the fraction $W\left(w^{*}\right) L\left(l^{*}\right)$ will choose both not to marry and not to have sex with their partner. Therefore, the fraction of the age- $j$ population that has never had sex is

$$
\frac{v_{j}}{\sigma^{j-1}}=\left[1-\mu+\mu W\left(w^{*}\right) L\left(l^{*}\right)\right]^{j}
$$

Now,

$$
\frac{d\left(v_{j} / \sigma^{j-1}\right)}{d \pi}=j\left[1-\mu+\mu W\left(w^{*}\right) L\left(l^{*}\right)\right]^{j-1} \mu\{W_{1}\left(w^{*}\right) L\left(l^{*}\right) \underbrace{\frac{d w^{*}}{d \pi}}_{+}+W\left(w^{*}\right) L_{1}\left(l^{*}\right) \underbrace{\frac{d l^{*}}{d \pi}}_{-}\} \gtreqless 0 .
$$

This expression is ambiguous because while safer sex leads to a decrease in the number of age- $j$ singles who are abstinent, via a drop in the threshold level of libido, $l^{*}$, it also increases the pool of age- $j$ singles, through a rise in the threshold value for marriage, $w^{*}$.

Additionally, there are age- $j$ marrieds who didn't have premarital sex. For example, at age $j$ there will be $\mu\left[1-W\left(w^{*}\right)\right] \sigma v_{j-1}$ individuals who marry but didn't have premarital sex. So, the fraction of the age- $j$ population that didn't have premarital sex is

$$
\frac{v_{j}+\mu\left[1-W\left(w^{*}\right)\right] \sum_{i=1}^{j} \sigma^{j+1-i} v_{i-1}}{\sigma^{j-1}} .
$$

The fraction of the age- $j$ single population that has never had sex is

$$
\frac{v_{j}}{s_{j}}=\frac{\left[1-\mu+\mu W\left(w^{*}\right) L\left(l^{*}\right)\right]^{j} \sigma^{j-1}}{\left[1-\mu+\mu W\left(w^{*}\right)\right]^{j} \sigma^{j-1}}=\left[\frac{1-\mu+\mu W\left(w^{*}\right) L\left(l^{*}\right)}{1-\mu+\mu W\left(w^{*}\right)}\right]^{j} .
$$

Proposition 29.6 (Premarital Sex). The fraction of the age- $j$ single population that has had premarital sex, $1-v_{j} / s_{j}$, is increasing in the odds of safe sex, $\pi$.

Proof. The proposition holds because

$$
\begin{aligned}
\frac{d\left(v_{j} / s_{j}\right)}{d \pi} & =j\left[\frac{1-\mu+\mu W\left(w^{*}\right) L\left(l^{*}\right)}{1-\mu+\mu W\left(w^{*}\right)}\right]^{j-1} \mu \\
& \times \frac{\left[1-\mu+\mu W\left(w^{*}\right)\right] W\left(w^{*}\right) L_{1}\left(l^{*}\right) d l^{*} / d \pi-(1-\mu) W_{1}\left(w^{*}\right)\left[1-L\left(l^{*}\right)\right] d w^{*} / d \pi}{\left[1-\mu+\mu W\left(w^{*}\right)\right]^{2}}<0 .
\end{aligned}
$$




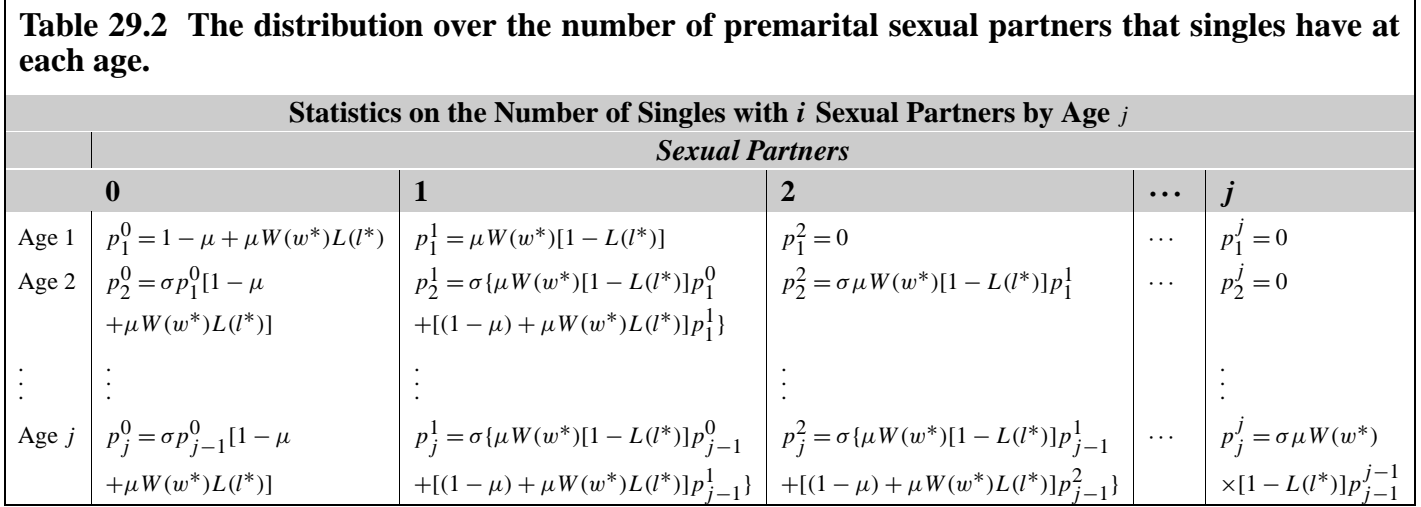

\subsubsection{Number of sexual partners}

A variable of interest is the average number of premarital sexual partners that an age- $j$ person has. Let $p_{j}^{i}$ be the number of singles that have had $i$ sexual partners by age $j$. First, given the model's timing structure, $p_{j}^{i}=0$ for $i>j$. Second, for an age- $j$ single to have 0 sexual partners they must have had 0 sexual partners at age- $(j-1)$, survive into period $j$ with chance $\sigma$, and then either remain unmatched with probability $1-\mu$ or match with odds $\mu$, decide not to marry with likelihood $W\left(w^{*}\right)$, and not to have premarital sex with chance $L\left(l^{*}\right)$. Therefore, $p_{j}^{0}=\sigma p_{j-1}^{0}\left[1-\mu+\mu W\left(w^{*}\right) L\left(l^{*}\right)\right]$, with $p_{0}^{0} \equiv 1 / \sigma$. Likewise, for an age- $j$ single to have $j$ sexual partners they must have had $j-1$ sexual partners at age- $(j-1)$ which happens with probability $p_{j-1}^{j-1}$, survive with chance $\sigma$, then match and remain single in period $j$ with odds $\mu W\left(w^{*}\right)$, and finally decide to have sex with probability $1-L\left(l^{*}\right)$. This implies $p_{j}^{j}=\sigma \mu W\left(w^{*}\right)\left[1-L\left(l^{*}\right)\right] p_{j-1}^{j-1}$.

Finally, there are exactly three ways for an age- $j$ single to have $i$ sexual partners, where $i<j$. First, they could have had $i-1$ partners at age $j-1$, survive, match, remain single, and then have decided to have sex. There will be $\sigma \mu W\left(w^{*}\right)\left[1-L\left(l^{*}\right)\right] p_{j-1}^{i-1}$ people in this category. Second, they could have had $i$ sexual partners in period $j-1$, survive, but not match. There will be $\sigma(1-\mu) p_{j-1}^{i}$ such singles. Third, they could have had $i$ sexual partners in period $j-1$, survive, match, remain single, and decide not to have sex. The number of singles here is $\sigma \mu W\left(w^{*}\right) L\left(l^{*}\right) p_{j-1}^{i}$. Hence, $p_{j}^{i}=$ $\sigma\left\{\mu W\left(w^{*}\right)\left[1-L\left(l^{*}\right)\right] p_{j-1}^{i-1}+\left[(1-\mu)+\mu W\left(w^{*}\right) L\left(l^{*}\right)\right] p_{j-1}^{i}\right\}$.

The number of sexual partners that a person has before marriage can be computed using the statistics in Table 29.2. Let $q_{j}^{i}$ be the number of age- $j$ married people that have had $i$ partners before marriage. First, to have had $j-1$ partners by age $j$ you must have had $j-1$ partners while single up to age $j-1$, survived to age $j$, and then gotten married. So, the number of age- $j$ married people who have had $j-1$ partners is $q_{j}^{j-1}=\sigma \mu\left[1-W\left(w^{*}\right)\right] p_{j-1}^{j-1}$.

Second,

$$
q_{j}^{i}=\sigma \mu\left[1-W\left(w^{*}\right)\right] p_{j-1}^{i}+\sigma^{2} \mu\left[1-W\left(w^{*}\right)\right] p_{j-2}^{i}+\cdots+\sigma^{j-i} \mu\left[1-W\left(w^{*}\right)\right] p_{i}^{i},
$$

for $0<i \leq j-1$. On this, note that the earliest you can have $i$ partners is at age $i$. At age $i$ there will be $p_{i}^{i}$ such singles. Out of this group, $\sigma \mu\left[1-W\left(w^{*}\right)\right] p_{i}^{i}$ will marry at age $i+1$ and then survive to 
period $j$ with probability $\sigma^{j-i-1}$. Likewise, $p_{h}^{i}$ singles of age $h$, for $i \leq h \leq j-1$, will have had $i$ partners at age $h$, then gotten married at age $h+1$ with probability $\sigma \mu\left[1-W\left(w^{*}\right)\right]$, and subsequently survived to age $j$ with probability $\sigma^{j-h-1}$.

Last, for an age- $j$ married person to have 0 sexual partners they must have survived until age $j$ and gotten married without having premarital sex. They could marry at any age up to and including $j$. Thus, to summarize the cases,

$$
q_{j}^{i}=\mu\left[1-W\left(w^{*}\right)\right] \sum_{h=i}^{j-1} \sigma^{j-h} p_{h}^{i}, \text { for } 0 \leq i \leq j-1 .
$$

Empirically, it may be desirable to include the person that you marry as a partner.

Now, the average number of sexual partners that an age- $j$ married person has is

$$
\frac{\sum_{i=0}^{j} i q_{j}^{i}}{\sum_{i=0}^{j} q_{j}^{i}}=\frac{\sum_{i=0}^{j} i q_{j}^{i}}{m_{j}}
$$

where $m_{j}$ is the total number of people who are married at age $j$ as defined in Table 29.1. A reasonable conjecture might be that the average number of premarital partners that an age- $j$ married person has is increasing in the efficacy of contraception, $\pi$. While this can't be established theoretically speaking, it still can be true quantitatively.

\subsubsection{Out-of-wedlock births}

The fraction of matched singles that have an out-of-wedlock birth, $o$, is given by $o=(1-\pi)[1-$ $L\left(l^{*}\right)$ ]. This can rise or fall with $\pi$, depending on whether

$$
\frac{d o}{d \pi}=\underbrace{-\left[1-L\left(l^{*}\right)\right]}_{\text {IMPROVED CONTRACEPTION }}+\underbrace{(1-\pi) \frac{1-d L\left(l^{*}\right)}{d \pi}}_{\text {INCREASE IN SEXUAL ACTIVITY }} \gtreqless 0 .
$$

This is an elasticity question that can be rephrased as

$$
\frac{d o}{d \pi} \gtreqless 0 \text { as } \frac{(1-\pi)}{\left[1-L\left(l^{*}\right)\right]} \frac{1-d L\left(l^{*}\right)}{d \pi} \gtreqless 1 .
$$

The shape of the distribution function $L(l)$ will determine whether out-of-wedlock births for matched singles rise or fall with the odds of safe sex, $\pi$.

For the population at large, Eq. (29.5) gives the fraction who have not married by age $j$. Out of this group, the portion $\mu$ will be matched in the current period. The fraction $1-W\left(w^{*}\right)$ will marry, while the slice $W\left(w^{*}\right)$ won't. Therefore the fraction of the nonmarried population that will be matched and remain single is given by $\mu W\left(w^{*}\right) /\left\{1-\mu\left[1-W\left(w^{*}\right)\right]\right\}$. Out of this, the cut $1-L\left(l^{*}\right)$ will be sexually 
active. Consequently, given the failure rate, $1-\pi$, the fraction of the population up to and including age $j$ that has an out-of-wedlock birth in the current period is

$$
(1-\pi)\left[1-L\left(l^{*}\right)\right] \frac{\mu W\left(w^{*}\right)}{1-\mu\left[1-W\left(w^{*}\right)\right]} \frac{\sum_{i=1}^{j} s_{i}}{\sum_{i=1}^{j} \sigma^{i-1}} .
$$

Clearly, this can rise or fall with $\pi$, because, as was just shown, $(1-\pi)\left[1-L\left(l^{*}\right)\right]$ can rise or fall in $\pi$.

\subsection{Calibration}

\subsubsection{The procedure}

The quantitative analysis focuses on two periods, namely 1900 and 2000. A steady state for the model is computed for each of these periods. The model period is taken to be four months (or a tertile). Functional forms for the distribution functions governing libido, $l$, and marriageability, $w$, need to be chosen. Let libido be governed by a Weibull distribution. Specifically,

$$
L(l)=1-\exp \left[-(l / \lambda)^{\eta}\right], \text { for } \lambda, \eta>0,
$$

where $\lambda$ and $\eta$ are the scale and shape parameters, respectively. Assume that marriageability has an exponential distribution. In particular,

$$
W(w)=1-\exp [-(w / \xi)], \text { for } \xi>0
$$

Here $\xi$ is the mean of the marriageability distribution.

Two criteria are used for selecting parameter values. First, the values for some parameters can be assigned from a priori information. Second, the remaining parameter values are chosen so that the model matches, as well as possible, a set of data targets. Start with the parameters chosen on the basis of a priori information. Denote the discount factor, sans the survival rate, by $\delta$. Given this, $\beta=\sigma \delta$. The discount factor, $\delta$, is given the standard value of $0.96^{1 / 3}$. People are assumed to have a life span relevant for marriage decisions of 30 years. The four month survival rate, $\sigma$, is set at $0.9925^{1 / 3}$ for 1900 and $0.9991^{1 / 3}$ for $2001 .^{4}$ The failure rates for contraception are taken directly from the data, as discussed below. Last, the mean for the marriageability distribution, or $\xi$, is just a normalization. On this, suppose that a solution to the model has been found for some value of $\xi$. The same solution obtains for $\phi \times \xi$, for $\phi>1$, if $a, O$, and $\lambda$ are also multiplied by $\phi$. What matters for an individual's choices are the relative values of abstinence, premarital sex, and marriage. So, set $\xi=1.0$.

The values for the rest of the parameters are selected to hit a set of stylized facts. Let $D_{j}$ represent the $j$-th data target. Likewise, $P_{j}(\rho)$ is the model's prediction for the $j$-th target, as a function of the parameters, $\rho \equiv(a, \mu, O, \lambda, \eta)$, to be selected. These parameters are picked to minimize the relative

4 The yearly survival probabilities are calculated for females ages 15 to 45, based on Table 10 in Arias (2004). 


\begin{tabular}{|c|c|c|c|}
\hline \multicolumn{4}{|c|}{$\begin{array}{l}\text { Table } 29.3 \text { Parameter Values. The parameters set on the } \\
\text { basis of ex ante information are discussed in the text. The } \\
\text { remaining parameters are selected in line with the mini- } \\
\text { mization routine }(29.10) \text {. }\end{array}$} \\
\hline \multicolumn{4}{|c|}{ Parameter Values } \\
\hline Parameter & Value, 1900 & Value, 2000 & Description \\
\hline \multicolumn{4}{|c|}{ Set using ex ante information } \\
\hline$J$ & 90 & 90 & \# of periods \\
\hline$\delta$ & $0.96^{1 / 3}$ & $0.96^{1 / 3}$ & discount factor \\
\hline$\sigma$ & $0.9925^{1 / 3}$ & $0.9991^{1 / 3}$ & survival rate \\
\hline$\pi$ & $(1-0.72)^{1 / 3}$ & $(1-0.28)^{1 / 3}$ & $\operatorname{Pr}($ safe sex) \\
\hline$\xi$ & 1.0 & 1.0 & exponential, mean- $w$ \\
\hline \multicolumn{4}{|c|}{ Set via calibration routine } \\
\hline$\lambda$ & 0.085 & 0.085 & Weibull, scale- $l$ \\
\hline$\eta$ & 22.723 & 22.723 & Weibull, shape- $l$ \\
\hline$a$ & 0.027 & 0.027 & abstinence \\
\hline$O$ & 0.1806 & 0.1806 & out-of-wedlock birth \\
\hline$\mu$ & 0.3359 & 0.3359 & matching rate \\
\hline
\end{tabular}

prediction errors of the model. Therefore, $\rho$ solves the minimization problem

$$
\min _{\rho} \sum_{j=1}^{18} \omega_{j}\left[\frac{D_{j}-P_{j}(\rho)}{D_{j}}\right]^{2},
$$

where $\omega_{j}$ is the weight placed on target $j$. The set of targeted stylized facts is (where $\omega_{j}=1$ unless indicated otherwise):

1. The median age of marriage in 1900 and 2000.

2. The fraction of women by the three age groups $15-24,25-34$, and $35-44$ who had ever been married in 1900 and 2000. Each of the three age groups for a year has a weight of $1 / 3$.

3. The fraction of women by the three age groups $15-24,25-34$, and $35-44$ who had premarital sex in 1900 and 2004. Again, each of the three age groups for a year is weighted by $1 / 3$.

4. The number of out-of-wedlock births per 1,000 unmarried women in 1920 and 1998.

5. The number of partners (including future husband) before marriage in 1900 and 2000.

The parameters values that result from the calibration procedure are listed in Table 29.3. All parameters values are kept constant across the two steady states, except for the failure rate of contraception, which is discussed now.

\subsubsection{The failure rate for contraception, 1900 to $2015-2018$}

An important ingredient in the quantitative analysis is the failure rate for contraception. Fig. 29.12 shows the dramatic decline in the failure rate for contraception starting in 1900 and moving forward to 2015-18. The failure rate gives the odds of a woman becoming pregnant if she has sex at the normal 


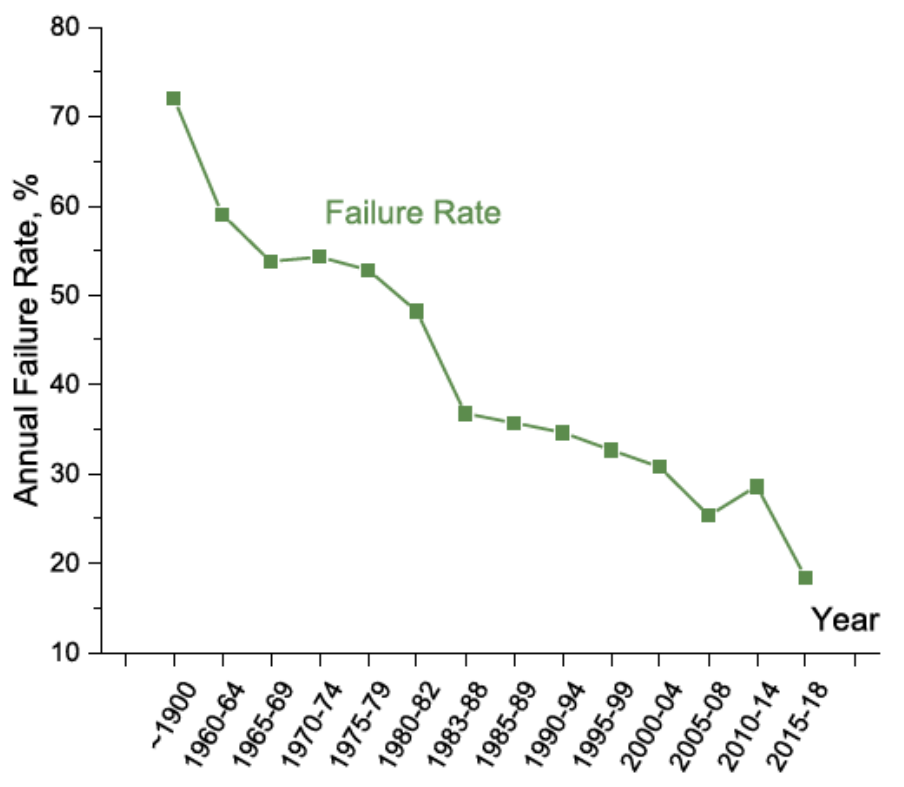

FIGURE 29.12

The annual failure rate for contraception, 1900 to 2015-18. The failure rate series is predicated upon the effectiveness of the contraceptive technologies available at each point in time as well as the usage distribution by women.

frequency for a period of one year. For each year the series harnesses the frequency distribution over the contraceptive practices used by women. This will depend on both the contraception technologies that are available at the time and their diffusion among sexually active women. The latter hinges upon the dissemination of information about, and the dispensation of, contraception. It also takes into account that some women won't use any method, including just withdrawal. Then, to compute the overall failure rate, the failure rate for each contraception is averaged across the different practices using the observed frequency distribution for usage. As can be seen, engaging in premarital sex in 1900 would have been very risky given the 72 percent odds of pregnancy. By 2015-18, the odds had dropped to 18 percent. The failure rate for the year 2000 steady state is set to 28 percent, the average failure rate over the 2000-14 period. Further detail on the construction of the failure rates is provided in Appendix C Data sources.

\subsubsection{Findings}

The upshot of the calibration procedure is presented in Table 29.4. First, between 1900 and 2000 the median age of marriage in the United States rose from 21.9 to 25.1 years. The model does a good job replicating this fact, with the median age of marriage moving up from 21.15 to 25.44 years. In the United States there was a big drop between 1900 and 2000 in the percentage of 15- to 24-year-old women that were ever married; an 11 percentage point drop from 29.62 to 18.17 percent. The model also displays an 11 percentage point drop, but too many women are married in this age group for both 


\begin{tabular}{|c|c|c|c|c|}
\hline $\begin{array}{l}\text { Table 29.4 Data Targ } \\
\text { are detailed in Appen }\end{array}$ & $\begin{array}{l}\text { S. All st } \\
\text { x C Da }\end{array}$ & $\begin{array}{l}\text { ics a } \\
\text { urce }\end{array}$ & vomen & ta so \\
\hline Data Targets & & & & \\
\hline Description & & & & \\
\hline & U.S. Data & Model & U.S. Data & Model \\
\hline Marriage & & & & \\
\hline $\begin{array}{l}\text { Median Age } \\
\text { Ever Married, \% }\end{array}$ & & 21.15 & 25.1 & 25.44 \\
\hline Age $15-24$ & 29.62 & 34.93 & 18.17 & 23.95 \\
\hline Age $25-34$ & 77.42 & 73.77 & 70.25 & 56.36 \\
\hline Age $35-44$ & 88.90 & 89.43 & 86.60 & 74.96 \\
\hline Premarital Sex, \% & & & & \\
\hline By Age 20 & 8 & 12 & 76 & 94 \\
\hline By Age 25 & 14 & 18 & 87 & 95 \\
\hline By Age 30 & 26 & 21 & 87 & 95 \\
\hline O.w.b.'s per 1,000 Singles & 8.7 & 3.40 & 44.3 & 33.6 \\
\hline Partners before Marriage & 2.8 & 1.18 & 7.0 & 8.2 \\
\hline
\end{tabular}

periods. Additionally, in the model for the year 2000 too few women have been married in the 25-to-34 and 35-to-44 age groups.

Second, single women became much more sexually active between 1900 and 2000. In the U.S. data for 1900, only 8 percent of women had experienced premarital sex by age 20, 14 percent by age 25 , and still only 26 percent by age 30 . The model mimics this low level of sexual activity well, with the corresponding numbers being 12,18 , and 21 percent. It over predicts the rise in premarital sexual activity. In the 2000 data 76 percent of women had engaged in premarital sex by age 20, a rise of 68 percentage points, while in the model 94 percent did, which represents an increase of 82 percentage points.

Third, over the period in question out-of-wedlock births in the United States shot up from 8.7 per 1,000 single women to 44.3. There is also a large increase in the model from 3.4 to 33.6. This represents an increase in the data of 35.6 pregnancies per 1,000 single women and an increase of 30.2 for the model. Additionally, single women now have sex with more partners than in the past. In 1900 a woman had on average 2.8 partners before marriage, including her future husband. The corresponding figure in the model is 1.2 , when the future husband is also counted. This rose to 7.0 partners in the 2000 data and to 8.2 for the model. Overall, the model does a good job explaining the targeted set of facts.

\subsubsection{Opening the black box}

The impact that parameter values have on the data targets can be analyzed by computing the model's Jacobian. The response of the $j$-th data target to a displacement in the value of the $i$-th parameter is calculated in elasticity form; i.e., $\left[\rho_{i} / P_{j}(\rho)\right] \times d P_{j}(\rho) / d \rho_{i}$. This is computed for all $i$ and $j$ involved in (29.10). It turns out that (locally) $a, \mu, O, \lambda$, and $\eta$ have a larger effect on sexual behavior in 1900 than in 2000. By contrast, the marriage statistics for 2000 display a bigger response to shifts in the parameters than do the ones for 1900. 


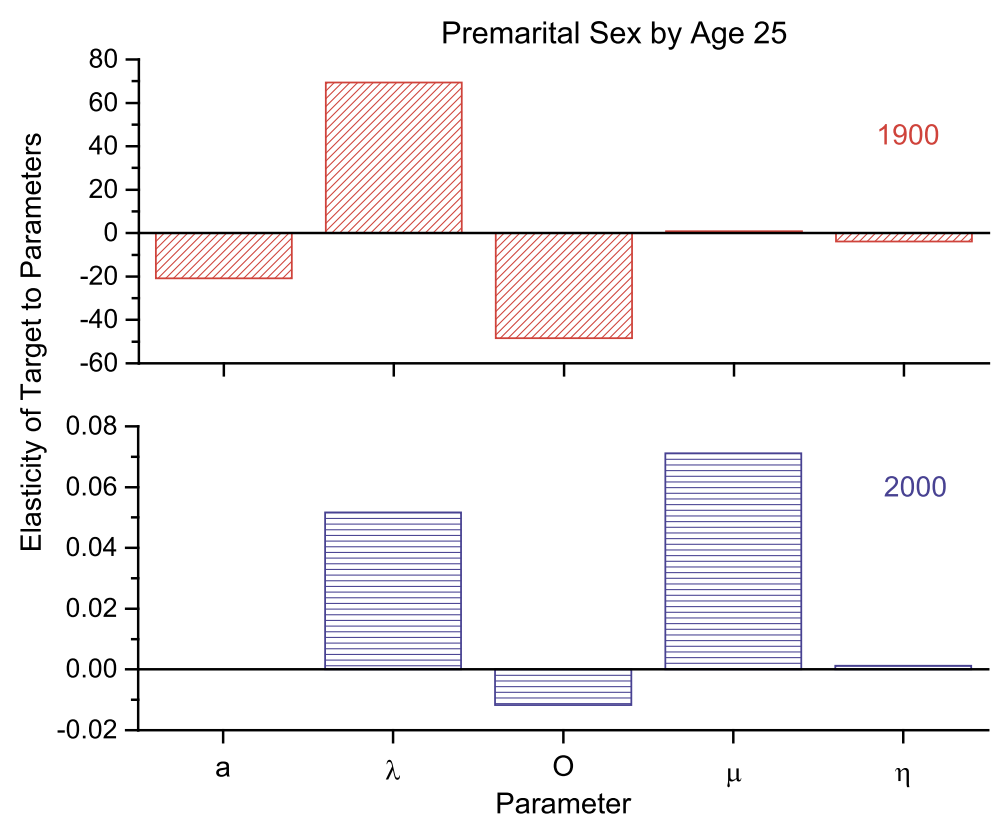

FIGURE 29.13

The part of the Jacobian showing the response of the percentage of women who had premarital sex before age 25 to a displacement in the parameters. The Jacobian is presented in elasticity form. Note that the units on the vertical scale for 1900 are much larger than the ones for 2000 .

Fig. 29.13 shows how the percentage of women who had premarital sex by age 25 responds in the two steady states to a change in parameter values. The percentage impact of a percentage movement in parameter values is much larger for the 1900 steady state than for the 2000 one, as can be seen by the units on the vertical axes. In 2000 almost all matched singles in the model are having premarital sex so the percentage reaction is muted, while in 1900 a small minority are so the percentage response is much bigger. The reactions make sense too. For example, increasing the utility from abstinence, $a$, or the cost of an out-of-wedlock birth, $O$, reduce the amount of premarital sex in 1900. Raising the libido scale parameter, $\lambda$, which increases the flow of women into premarital sex given the threshold, results in a higher level of premarital sex. The utility level for abstinence, $a$, has a negligible impact on premarital sex in 2000, because almost no matched singles are abstinent.

Fig. 29.14 does the same thing for the median age of marriage. Now a given percentage displacement in the parameter values has a much larger percentage impact on the 2000 steady state than for the 1900 one, as can be seen by the units on the vertical axes. This is understandable. In the 2000 steady state the vast majority of matched singles choose to have a sexual relationship. So, for example, they respond to an increase in the cost of out-of-wedlock births, $O$, by moving into marriage (or marrying earlier). A rise in the matching rate, $\mu$, leads to a delay in marriage for the 2000 steady state, but entices people to marry just slightly earlier in the 1900 one. This transpires because in the 2000 steady state the cost of waiting is lower because people can engage in non-marital sexual relationship. This 


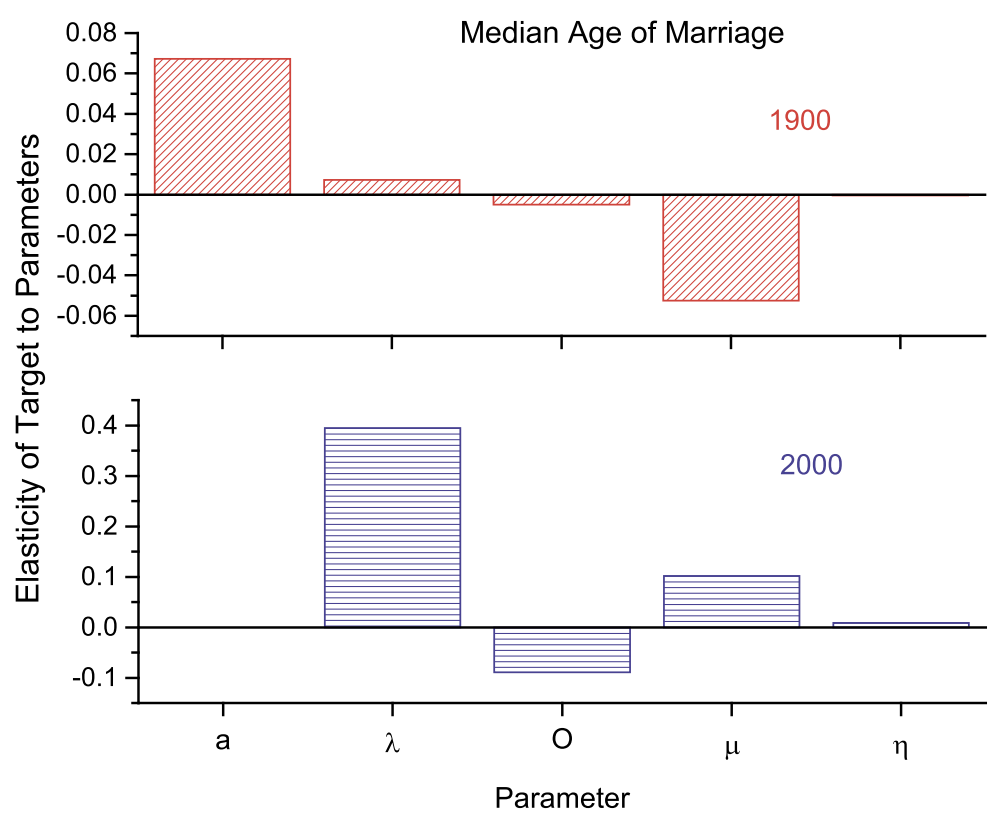

FIGURE 29.14

The part of the Jacobian showing the response of the median age of marriage to a displacement in the parameters. The Jacobian is presented in elasticity form. Note that the units on the vertical scale for 2000 are much larger than the ones for 1900, the opposite of Figure 29.13.

opportunity is more costly in the 1900 steady state, so people are less picky about their mate, and hence marry earlier.

\subsection{Conclusions}

While fertility has been controlled for eons, premarital sex would have been too risky for women historically. This began to change in the 19th century when contraceptive technology improved and information about contraception disseminated (Section 29.3). The 19th and 20th centuries saw improvements in condoms and spermicides, and the introduction of diaphragms, IUDs, and the pill. Just as important was the dissemination of information about contraception, often at personal risk for the providers. In America this started and ended with the crusaders Dr. Charles Knowlton and Margaret Sanger. The hypothesis here is that advancement in contraception led to a rise in premarital sex, an increase in out-of-wedlock births, and a fall in the fraction of the population that is married.

To address this hypothesis a marital search model is constructed. Each period a single may meet a partner. A person can choose to marry their partner or not (Section 29.5). If not, they can decide whether to have a premarital sexual relationship with the person (Section 29.6). The risk of a premarital sexual relationship is an out-of-wedlock birth. As contraception improves this risk is mitigated. It is shown 


\section{Chapter 29 The wife's protector}

theoretically that a drop in the failure rate for contraception leads to a decline in the rate of marriage (Section 29.5), an increase the fraction of singles who are sexually active (Section 29.6), a rise in the proportion of the population that is never married (Section 29.7), and a delay in the average age of marriage (Section 29.7).

The theoretical model is then confronted with the U.S. data (in Section 29.8). The quantitative analysis focuses on two periods in U.S. history; viz, 1900 and 2000. To start with, a time series is constructed measuring the efficacy of contraception. It is shown that the odds of a pregnancy for a sexually active woman dropped dramatically between 1900 and 2015-18. This made sex much safer for singles. The question then asked is whether the model can explain, as a function of technological progress in contraception, the following set of facts: the observed decline in marriage between 1900 and 2015-18, the rise in premarital sex, the increase in out-of-wedlock births, and the uptick in the number of sexual partners before marriage. The answer is yes.

A review of the relevant economics literature on marriage is presented now.

\subsection{Literature review}

\subsubsection{Contraception and the age of marriage}

An increasing use of birth control may be a cause of earlier marriage. For if a young couple can contemplate a marriage without a baby within a year, and hence with only two to provide for, and perhaps with the bride working at a paying job, we think there would be more marriage than if a baby is pretty sure to come within a year and the mother unable to earn any money.

Against this argument is the idea held by some that a young woman practicing birth control could have sexual intercourse without marrying and without becoming a mother, hence she can have a man without marrying; and similarly a man can have a woman without marriage. Thus marriage might be discouraged by the spread of birth control. Ogburn and Nimkoff (1955, pp. 89-90)

As a theoretical proposition, Ogburn and Nimkoff (1955) thought that the impact of contraception on the age of marriage could go either way. While they note that "(i)t is very difficult to test these ideas with data," they felt that the first hypothesis had more currency given that the age of marriage was decreasing at the time-note the dip in the median age of marriage between 1940 and 1960 shown in Fig. 29.1. Goldin and Katz (2002) advance a more modern version of this idea. They highlight two ways in which better contraception, the pill, changed the lives of college-educated women in the United States. First, the pill made the returns to investment in professional careers, such as law and medicine, less uncertain by allowing women to better time their fertility decisions. Second, the pill had a thicker marriage market effect: as more women delayed their entry into marriage, each individual woman became less concerned about being left out in the marriage market due to her career choice. In their empirical analysis, Goldin and Katz (2002) exploit variations across U.S. states in the access of young unmarried women to the pill. Their "most persuasive evidence for a role of the pill is that its initial diffusion among single women coincided with, and is analytically related to, the increase in the age at first marriage and the increase in women in professional degree programs" (p. 767). 
Now, it is clear that fertility was under control well before the 1960s, as Fig. 29.4 showed. This is not to say that family planning policies, especially for developing countries, are not important. ${ }^{5}$ Also, the number of sexually-active single women had risen dramatically before this time-Fig. 29.3. Furthermore, you can go to professional school while married. This is more common outside of the United States. The take off in women going to professional schools started after 1972. The flow of women into higher education had started well before this though. By 1972, 42 percent of bachelors degrees, 41 percent of masters degrees, and 18 percent of doctorates went to women, which amounted to 42 percent of all non-professional degrees. The respective numbers in 1900 were 19 percent, 19 percent, 8 percent, and 19 percent. The year 1972 was also when Title IX of the Education Amendments was signed into law. The law prohibited discrimination against women in any federally-funded education program. Goldin and Katz's (2002) defense is that its guidelines were not complete until 1975. While Title IX's statutory language was brief, it still would have been law upon enactment in 1972. It's likely that colleges and universities changed their admission policies before 1975, especially since there was uncertainty about what they would be legally liable for. In fact, one could argue that the passage of Title IX was itself a reaction to the changing place of women in education and the workplace. On this, see Greenwood et al. (2017) for a model where the passage of women's rights is an endogenous function of the state of the economy. Last, Meyers (2017), who revisits the empirical analysis by Goldin and Katz (2002), finds that the pill itself had little effect on the age of first marriages and births, while liberalized access to abortion had a much larger effect. So, the power of the pill, while important, may be overstated.

Before the pill was available to unmarried women, between its approval by the FDA in 1960 and the late 1960s or early 1970s, only married women could access it. Indeed, many U.S. states reduced the legal age of marriage from 21 to 18 during this period. According to Edlund and Machado (2015), these changes allowed women to marry early, which would be in line with Ogburn and Nimkoff's (1955) first idea. Combined with the pill, however, this also allowed them to widen the window between marriage and first birth and improve educational and professional outcomes. Gershoni and Low (2018a) document how the availability of in vitro fertilization in Israel has led to an increase in the average age at first marriage. In related work, Gershoni and Low (2018b) discuss how this increased education levels for women and resulted in higher paying careers. (Interestingly, Ogburn and Nimkoff (1955) discuss the transplantation of ova in their book, but speculated that its effect on the family would be negligible.)

\subsubsection{Premarital sex and out-of-wedlock births}

Technological advance in contraception allowed women to separate sex from marriage. This led to a dramatic increase in the fraction of women who engaged in premarital sex during the 20th century; again see Fig. 29.3. Yet, despite the improvements in contraceptive technology, out-of-wedlock births increased as well. Greenwood and Guner (2010) study premarital sex among teenagers within the context of an equilibrium matching model. In the model individuals rationally weigh the costs and benefits from this risky activity. Better contraceptives lower the expected cost of premarital sex. In

\footnotetext{
5 Cavalcanti et al. (2020) introduce unwanted births into a model of fertility decisions and growth, and show that family planning programs, which reduce the number of unwanted pregnancies, can generate significant gains in the educational attainments of children and hence GDP.
} 


\section{Chapter 29 The wife's protector}

their quantitative analysis better contraceptives result in both an increase in the fraction of teenagers having sex and the fraction of them becoming pregnant.

Akerlof et al. (1996) also focus on this puzzle. They suggest that better contraceptives, coupled with the availability of abortion, led to the disappearance of shotgun marriages, and as a result there was an increase in out-of-wedlock first births. In their framework prior to a sexual relationship single women may or may not ask for an implicit promise of marriage in the event of pregnancy. With the advance of contraception and the legalization of abortion, men can choose among many sexually active single women. Some single women who become pregnant may be willing to have an abortion, others won't. Competition on the marriage market may lead to women who are opposed to abortion being reluctant to ask for a promise of marriage should a pregnancy occur. But, why would men abide by such an implicit promise? (I.e., their equilibrium is not subgame perfect.) This is left unanswered in Akerlof et al. (1996).

On the basis of the observed decline of shotgun weddings, Kennes and Knowles (2019) argue that an important ingredient in the rise of out-of-wedlock births is an increase in the value of single life with children relative to marriage. Their vehicle for analysis is a repeated-matching model where women are heterogeneous in the number of previous children and where singles make decisions each period regarding their sexual activity, birth control, abortion, and whether to marry if pregnant. Low take-up rates of the pill and the availability of abortion are critical features in their analysis. Kennes and Knowles (2019) consider a number of candidates, such as the advent of legal abortion, lower divorce costs, and increased frictions in shotgun weddings, that might be responsible for the decline in shotgun marriages. Other things might also have reduced the value of marriage relative to single life with children: more generous welfare benefits, rising living standards together with the advent of labor-saving household technologies, and a lessening of the stigma associated with an out-of-wedlock birth.

Premarital sex and out-of-wedlock births were stigmatized in yesteryear in order to dissuade premarital sexual activity. Since societies then were much poorer than ones today, out-of-wedlock births placed an enormous financial burden on families, churches, and states. Fernandez-Villaverde et al. (2014) model the formation and evolution of such social norms. As premarital sexual activity became safer, parents, churches, and governments had less incentive to stigmatize premarital sex, given that socialization is a costly activity. The relaxation of sexual norms operated to reinforce the effect that technological advancement in contraception had on the rise in premarital sex and out-of-wedlock births. Fernandez-Villaverde et al. (2014) formalize this intuition in a model of intergenerational preference transmission. For models of preference transmission in other contexts, see Becker (1993), Bisin and Verdier (2001), and Doepke and Zilibotti (2008).

\subsubsection{Other factors affecting the timing of marriage}

Clearly factors other than contraceptives affect the timing of marriage. Browning et al. (2014), Greenwood et al. (2017), and Stevenson and Wolfers (2007) provide reviews of the literature.

\subsubsection{Rising wages}

In his classic treatment of the topic, Becker (1991, p. 350) states that "the family in the United States changed more rapidly (since 1950) than during any equivalent period since the founding of the colonies. I believe that a major cause of these changes is the growth in the earning power of women as the 
American economy developed." Higher relative earnings reduce the gains from marriage for women and allow them to be more choosy between married and single life. Regalia and Rios-Rull (2001) formalize this idea in a quantitative model and show that increases in the relative earnings of women can potentially account for almost ninety percent of the observed rise in the share of single women since the mid-1970s. Shephard (2019) also focuses on the effects of a narrowing gender wage gap on marital outcomes. He builds a life-cycle equilibrium model with endogenous human capital accumulation, fertility, and home production to study time allocation and marriage decisions. His simulations show that the decline in the gender wage gap since the 1980s is able to generate an increase in female employment, a decline in male employment, an increase in the age-of-first marriage for women, and a reduction in the marital age gap between men and women.

Other aspects of the wage structure can also affect the incentive to marry. Olivetti (2006) documents that the returns to labor market experience increased for women since the 1970s and this was an important factor in generating rising female labor-force participation. Caucutt et al. (2002) show that, within a matching model of marriage, this will also increase the incentives of women to delay both fertility and marriage. Santos and Weiss (2016), instead, focus on the rising labor income volatility since the 1970s, and show that if marriage involves consumption commitments, such as children or housing, then a heightening in income volatility will delay entry into marriage.

\subsubsection{Household technologies}

Another key force that shaped families in the United States and elsewhere was the dramatic improvements in households technologies. Improvements in household durables freed women from housework and allowed them to enter the labor force-see Greenwood et al. (2005a, 2005b). (Relatedly, Albanesi and Olivetti, 2016, argue that advances in maternal medicine facilitated the entry of young women into the workplace.) These forces reduced the benefit from a traditional marriage; to wit, a breadwinner husband and a housekeeper wife. Greenwood and Guner (2009) integrate home production into a search model of marriage, and show that better household technologies can account for a significant part of the rise in divorce, the fall in marriage, and the increase in married female labor-force participation that occurred during the later half of the 20th century. According to Greenwood and Guner (2009, p. 233), "the reduction of the economic benefits of marriage allowed the modern criteria of mutual attraction between mates to come to the fore, a trend 'from economics to romance' in the words of Ogburn and Nimkoff (1955)." They also show how improvements in household technology and increases in income can explain the increase in marriage between 1940 and 1960-for one more time, recall Fig. 29.1. 6

\footnotetext{
6 The idea is that technological progress in the household sector, together with rising living standards, at first made it easier for young couples to leave their parents' homes and establish married households and then later on in time for singles to leave their parents' homes and establish single households before marriage. That is, there is a trend over time toward smaller and smaller households.
} 


\section{Chapter 29 The wife's protector}

As marriage declined in the United States, there has also been an upswing in assortative mating, the tendency of people with similar educational attainments to marry each other (Chiappori et al., 2017, and Greenwood et al., 2014). Greenwood et al. (2016) develop a model, with heterogeneous agents, of marriage, divorce, educational attainment, and married female labor-force participation. They show how a hike in the college premium together with labor-saving technological progress in the household sector, led to a decline marriage, an increase married female labor-force participation, and widening inequality in the United States. The induced changes in married female labor-force participation and marriage play an important role in amplifying the impact of shifts in the wage structure on inequality.

\subsubsection{The welfare state}

The expansion of welfare state, in particular social assistance to single mothers with children, has often been pointed to as another important force that has shaped U.S. families. There are mixed views about this idea. The empirical evidence in favor of the idea, which relies on cross-time and cross-state variations in welfare policies, has been weak-see Moffitt (1992) for an early review and Moffitt et al. (2020) for a more recent analysis. Structural models such as Aiyagari et al. (2000) and Greenwood et al. (2000) predict that less generous welfare payments should reduce the number of single women. In line with this prediction, Low et al. (2018) show that the 1996 welfare reform did result in more married women.

\subsubsection{Lack of marriageable men}

A large literature in sociology and demography, emphasizes the lack of marriageable men as a potential factor for the decline of marriage in the United States. The basic idea, following Wilson and Neckerman (1986), is that low wage growth, declining manufacturing, and rising incarceration in recent decades made marriageable men scarce. Schneider et al. (2018) document, for example, that reduced economic prospects and increased risk of incarceration contributed significantly to the decline of marriage in the United States over the last 45 years. Incarceration has also been proposed as a factor that can explain why blacks marry at a much lower rate than whites in the United States. Exploiting cross-state U.S. data, Charles and Luoh (2010) find a strong negative effect of male incarceration rates on the likelihood of women ever getting married. Building on this intuition, Caucutt et al. (2018) develop an equilibrium search model of marriage, divorce, and labor supply that takes into account the transitions between employment, unemployment, and prison for individuals by education, gender, and race. They show that if black men had the same employment and prison transitions as whites, then about half of the racial marriage gap would be eliminated.

\subsubsection{Changes in the sex ratio}

Since historically it took two sexes, a man and a woman, to form a marriage, the sex ratio (defined as the number of single men to single women) can affect marriage decisions. If there is an imbalance in the sex ratio, whoever is on the short side of the market will have a harder time to find a partner. When a marriage is formed, the sex in short supply will have a higher bargaining power. These features emerge in standard search and matching models (e.g., Greenwood et al., 2000). 
What can generate an imbalanced sex ratio? Some candidates are changes in population growth rates (say a baby boom or baby bust), male incarceration, sex-biased migration, and wars. Angrist (2002) exploits, as a natural experiment, variations in migration flows during the early 20th century in the United States. He finds that migration, which increased the size of the male population more for some ethnic groups than others, improved marriage prospects for women. In particular, it increased the likelihood of marriage for women and reduced female labor-force participation. The latter is a reflection of a tilt in household bargaining power toward women. Angrist (2002, p. 997) provides a quote from a Moroccan female immigrant saying "Every day I meet someone better. I am waiting for the best." Bronson and Mazzocco (2017) document, by analyzing nearly century of U.S. data, that higher cohort sizes are associated with lower marriage rates for both men and women. They find that variations in cohort sizes can explain a large variation in marriage rates since the 1930s.

Recent research suggests that the theoretical link between sex ratios and marriage can be complex. An excellent example is Knowles and Vandenbroucke (2019) who analyze the aftermath in France of World War I. They show that after World War I marriage rates increased for both men and women in France, despite a large drop in the sex ratio. They build a directed search model of marriage in which young and old men and women have different preferences for marriage. In particular, young men are less inclined to marry than either old men or young and old women. Due to bleak economic prospects, World War I was not a good time to marry and raise a family-see Vandenbroucke (2014) for an analysis of this. This impacted the marriage rates for older men more than younger ones, because the latter weren't as likely to marry. As a result the stock of single older men was affected more than the stock of younger ones. Consequently, following the war the stock of marriageable men was high despite large casualties; furthermore, casualties were higher for younger men which compounded the situation.

Bronson and Mazzocco (2018) note that standard models of marriage would have a difficult time explaining how an increase in cohort size leads to a fall in the marriage rates for both men and women. Since women usually marry older men an increase in a cohort would reduce the ratio of marriageable men to women. A standard model would predict a fall in the marriage rate for women and a rise in the one for men. To overcome this prediction, they adapt the standard model so that men can undertake a pre-marital investment that increases their probability of meeting a potential spouse (as in Chiappori et al., 2009). When the population is growing and men are in a relatively better position in the marriage market, they have lower incentives for pre-marital investment, which can result in lower marriage rates for them as well as women. Last, as discussed earlier, Caucutt et al. (2018) analyze how the high incarceration (and unemployment) rates for black males have reduced the stock of marriageable men and has led to low marriage rates for blacks. 


\title{
29.11 Appendix A Beers's specification of letters patent
}

\section{UNITED STATES PATENT OFFICE.}

J. B. BEERS, OF ROCHESTER, NEW YORK.

\author{
PREVENTING CONCEPTION.
}

Specification of Letters Patent No. 4,729, dated August 28, 1846.

To all whom it may concern:

Be it known that I, JoHN B. Beers, of the city of Rochester, in the county of Monroe and State of New York, have invented a

5 new Instrument, called the "wife's protector," the design of which is to Prevent conception; and $\mathbf{I}$ do hereby declare that the following is a full and exact description.

It consists of six separate pieces, viz,

10 hoop, band, joint, joint-pin, membranous covering, and handle.

It is constructed in the following manner:

The hoop (A) is made of a piece of oval wire, formed into a ring about an inch and

15 a half in diameter, and to this, is soldered the point (B), formed from a piece of hollow wire about $\frac{1}{2}$ an inch in length, which has two slots cut in it (C, C, ) about $\frac{1}{4}$ of an inch apart, to receive the end of the

20 handle (D, D, ) which forms the other half of the hinge or joint. The center of this joint, from one slot to the other, is flattened at right angles with the hoop (A) to which it is attached.

25 The handle consists of one piece of metal, (gold alloyed with platina is to be preferred on account of its great elasticity, and not being liable to change color.) It should be about eight inches in length, and about $\frac{1}{10}$

30 of an inch in width, except the end that is crooked, which is left larger merely for ornament. The other end is about $\frac{3}{8}$ of an inch in width, and has two longitudinal slits extending $t$ of an inch from the end, and

35 about $T_{\overline{1}} \overline{\mathrm{c}}$ of an inch from either edge, running parallel with the handle. The two outside planes are then formed into knuckles, to work like a hinge in the slots $(\mathrm{C}, \mathrm{C}$ ) cut in the joint $(B$,$) . The center F$ is cut off

40 even with the knuckles (D, D, and is intended to rest upon the flat surface between the slots, and act as a spring, leeping the hoop while in use at right angles. The two are then united, and kept in their place

15 by a joint-pin. The hoop is then covered with oil-silk, or some other thin membra nons substance ( $E$, ) and held in its place by a metallic band, made to slip snugly over the hoop and thus securing the edges of the covering between them. The edges of the 50 band are then to be burnished down smoothly; and lastly, the handle should be formed into shape, resembling the sectional view in the annexed drawing No. 2.

To use this instrument, the hoop is to be 55 pressed down upon the handle by the thumb of the right hand, turning it up edgewise, and then introduced into the vagina, when, immediately after, having passed the sphincter, and the bones of the pelvis, it 60 extends itself to its natural position, nearly at right angles with the rod or stem, and as it is farther introduced, the handle is to be turned downward $\frac{1}{4}$ of a circle. In this position the membrane on the hoop is made to 65 completely cover the os uteri, thus entirely preventing the semen from entering the uterus, without which, (it is assumed) conception can not take place.

While the rod aforesaid lies along the 70 lower side of the vagina, with a slight curve, to accommodate itself to the sphincter, and terminates in the angles above described, lying near the anus, and if properly adjusted, can not be felt by either party. 75 After coition, when the instrument is being withdrawn the spring joint permits the extension of the hoop to nearly a parallel line with the rod accommodating itself to the shape and size of the vagina, and bringing 80 the semen away with it.

What I claim as my invention, is-the particular combination of a covered hoop attached to a handle by a spring-joint as described and for the purposes above speci- 85 fied.

Witnesses:

\section{J. B. BEERS.}

DANIEL WOOD,

O. MORRTS.

Source: United States Patent and Trademark Office. 


\subsection{Appendix B Theory}

Proof of Proposition 29.5 (Mean and Median Ages of Marriage). Focus on the mean age of marriage, as given by Eq. (29.6). As can be deduced from Table 29.1, the average age of marriage can be rewritten as

$$
\frac{\sum_{i=1}^{j} i n_{i}}{\sum_{i=1}^{j} n_{i}}=\frac{\sum_{i=1}^{j} i s_{i-1}}{\sum_{i=1}^{j} s_{i-1}}, \text { with } s_{0} \equiv 1 / \sigma .
$$

Consider the distribution function given by $\left(\sum_{i=1}^{l} s_{i-1}\right) /\left(\sum_{i=1}^{j} s_{i-1}\right)$, for $0 \leq l \leq j$. Now, the odds of being around and single after $i-1$ periods are $s_{i-1}=\left[1-\mu+\mu W\left(w^{*}\right)\right]^{i-1} \sigma^{i-2}$. Therefore,

$$
\frac{\sum_{i=1}^{l} s_{i-1}}{\sum_{i=1}^{j} s_{i-1}}=\frac{1-\phi^{l}}{1-\phi^{j}}, \text { with } \phi \equiv\left[1-\mu+\mu W\left(w^{*}\right)\right] \sigma .
$$

It is easy to check the righthand side is decreasing in $w^{*}$. This implies that the distribution function is stochastically increasing in $w^{*}$ in the sense of first-order stochastic dominance; i.e., the odds of marrying by age $l$ have decreased, while the odds of marrying after age $l$ have increased. Trivially, the integer $i$ is increasing in $i$. Consequently, by the theorem of first-order stochastic dominance [see Hadar and Russell (1971)] the average age of marriage must be increasing in $w^{*}$ and hence $\pi$ by Proposition 29.1.

The median age of marriage lies between $l$ and $l+1$, where

$$
\frac{\sum_{i=1}^{l} n_{i}}{\sum_{i=1}^{j} n_{i}}=\frac{\sum_{i=1}^{l} s_{i-1}}{\sum_{i=1}^{j} s_{i-1}} \leq 0.5 \leq \frac{\sum_{i=1}^{l+1} n_{i}}{\sum_{i=1}^{j} n_{i}}=\frac{\sum_{i=1}^{l+1} s_{i-1}}{\sum_{i=1}^{j} s_{i-1}} .
$$

There are two cases to consider. The first case is where the median age of marriage moves out of the interval $[l, l+1]$. From the above analysis, the far righthand side is decreasing in $w^{*}$. This implies that the median age of marriage will increase in this situation. The second case is where the median age of marriage remains within the interval $[l, l+1]$. Here the median age of marriage is fixed at $(l+l+1) / 2=l .5$. So in the second case the median age of marriage is nondecreasing in the efficacy of contraception.

\subsection{Appendix C Data sources}

\subsubsection{Figures and tables}

- Fig. 29.1 (fraction of the female population, 18-29, never married, 1880-2015): The data for 1880-1990 is from the Historical Statistics of the United States: Millennial Edition (Table Aa614683)-Carter et al. (2006). The data for 2000-2015 is based on the authors' calculations from the U.S. Census Bureau's American Community Survey.

- Fig. 29.1 (median age at first marriage, 1880-2018): United States Census Bureau, Historical Marital Status Tables, Table MS-2. 


\section{Chapter 29 The wife's protector}

- Fig. 29.2 (percentage of births to unmarried women, 1920-2017): For 1920 and 1930, see Cutright (1972, Table 1, p. 383); for the data between 1940 and 1999, see Ventura and Bachrach (2000, Table 1, p. 17); for 1999-2013, see Curtin et al. (2014); for 2014, 2015, 2016, and 2017, see the National Vital Statistics Reports-Births: Final Data for the corresponding years.

- Fig. 29.2 (non-marital births by age group per 1,000 women): Computed for the years 1940 to 1990 from Historical Statistics of the United States (Tables Aa614-683 and Ab264-305). For the years 2000 and 2007, the numbers are calculated using the birth rates for unmarried women, as reported in the National Vital Statistics Reports, and the fraction of unmarried women, calculated using IPUMS USA.

- Fig. 29.3 (premarital sex): For birth cohorts pre-1900 to 1910-1919, the data is taken from Kinsey et al. (1953, Table 83, p. 339). The data for the later cohorts is from Wu et al. (2018, Table 3, p. 733).

- Fig. 29.3 (number of partners before marriage): The data for the birth cohorts from pre-1900 to 1910-1919 are from Kinsey et al. (1953, Table 78, p. 336). The numbers for the later cohorts are based on the authors' calculations from the National Health and Social Life Survey (NHSLS). The numbers presume that the woman had premarital sex with her future husband.

- Fig. 29.4 (total fertility rate for white women): The numbers for 1800 to 1990 are from the Historical Statistics of the United States (Table Ab52-117). For the years 1991 to 2015, the data comes from Martin et al. (2017, Table 4, p. 21).

- Fig. 29.4 (complementary cumulative distribution functions over children ever born): Historical Statistics of the United States (Table Ab498-535).

- Fig. 29.12 (annual failure rate for contraception, 1900 to 2015-18): The annual failure rate data is provided in the last column of Table 29.6. The series is constructed from the data presented in Tables 29.5 and 29.6 on the uses and effectiveness of contraception.

- Table 29.4 (data targets): The fraction of women ever married by age for 1900 comes from the Historical Statistics of the United States: Millennial Edition (Table Aa614-683). For the year 2000 the data is from the U.S. Census Bureau's brief "Marital Status: 2000." The number of out-ofwedlock births per 1,000 unmarried women in 1920 derives from Cutright (1972, Table 1, p. 383). The corresponding number for 1998 is taken from the Historical Statistics of the United States: Millennial Edition (Table Ab264-305). The fractions of women who had premarital sex in 1900 are taken from Kinsey et al. (1953, Table 83, p. 339). For 2004 the numbers are in line with Wu et al. (2018, Table 3, p. 733). In particular, the fraction for age 25 is set equal to the fraction found for age 30, which is what the Wu et al. (2018) data strongly suggests. For 1900 the number of partners before marriage is for the before-1900 cohort listed in Kinsey et al. (1953, Table 78, p. 336). The number for 2000 is based on the authors' calculations from the 1992 National Health and Social Life Survey (NHSLS) and pertains to women born between 1963 and 1972.

- Tables 29.5 and 29.6 (use and effectiveness of contraception): See the detailed discussion below.

\subsubsection{Contraceptive use}

Table 29.5 presents data on the use of contraception. For construction of the data before 1985, see Greenwood and Guner (2010). For 1985-2008, the numbers are taken from Mosher and Jones (2010, Table 3, p. 20). The data for 2010-18 are based on the authors' calculations from the National Survey of Family Growth (waves from 2006-10 to 2015-17). The usage of multiple contraceptives by users was 


\begin{tabular}{|c|c|c|c|c|c|}
\hline $\begin{array}{l}\text { Table } \\
\text { first p } \\
\text { time. }\end{array}$ & $\begin{array}{l}\text { Th } \\
\text { larit } \\
\text { luml }\end{array}$ & oblo & $\begin{array}{l}\text { hows } \\
\text { ourse } \\
\text { expre }\end{array}$ & $\begin{array}{l}\text { traceptio } \\
\text { arious p } \\
\text { l as perc }\end{array}$ & $\begin{array}{l}\text { se at } \\
\text { ts in } \\
\text { ges. }\end{array}$ \\
\hline Contrac & eptive I & e at $F$ & rst Prema & ital Intercou & rse, \% \\
\hline Period & None & Pill & Condom & Withdrawal & Other \\
\hline $1900-59$ & 61.4 & - & 9.42 & 11.19 & 17.99 \\
\hline $1960-64$ & 61.4 & 4.2 & 21.9 & 7.3 & 5.3 \\
\hline $1965-69$ & 54.2 & 8.6 & 24.0 & 9.5 & 3.7 \\
\hline $1970-74$ & 55.6 & 12.1 & 21.0 & 7.3 & 4.0 \\
\hline 1975-79 & 53.5 & 12.8 & 22.0 & 7.5 & 4.2 \\
\hline $1980-82$ & 46.9 & 14.2 & 26.7 & 8.4 & 3.8 \\
\hline $1983-88$ & 34.6 & 12.1 & 41.8 & 8.9 & 2.6 \\
\hline $1985-89$ & 34.0 & 13.7 & 43.2 & 6.8 & 2.3 \\
\hline 1990-94 & 30.3 & 15.4 & 47.3 & 4.5 & 2.5 \\
\hline 1995-99 & 27.5 & 17.0 & 48.7 & 5.0 & 1.8 \\
\hline 2000-04 & 24.2 & 17.0 & 53.4 & 2.5 & 2.9 \\
\hline 2005-08 & 15.9 & 15.1 & 56.4 & 7.1 & 5.4 \\
\hline 2010-14 & 19.4 & 21.9 & 51.3 & 3.3 & 4.2 \\
\hline 2015-17 & 10.0 & 19.9 & 56.2 & 3.4 & 10.5 \\
\hline
\end{tabular}

not reported until the 1995 NSFG. After that year, the sum across different methods is more than the total fraction who use any method. In Table 29.5 the percentage distribution across different methods is normalized to sum up to the total fraction who use any method. The "Other" methods category includes the use of diaphragms, cervical caps, IUDs, vaginal spermicides (such as foams, jellies, creams, and sponges), the rhythm method, and injections and implants which were introduced in the 1990s.

\subsubsection{Contraceptive effectiveness}

Table 29.6 gives the annual failure rates for condoms, the pill, withdrawal, and other methods. For construction of the failure rates before 2000, see Greenwood and Guner (2010). For 2000-2008, the failure rates for no method, the pill, condoms, and withdrawal are taken from Hatcher et al. (2004, Table 9-2, p. 226). For 2010-2014, the failure rates come from Hatcher et al. (2011, Table 3-2, p. 50). For 2015-2018, they derive from Hatcher et al. (2018, Table 3-2, p. 100).

Given the small number of people using other methods the results are not very sensitive to the assumption made regarding their effectiveness. In Greenwood and Guner (2010), the effectiveness of other methods is assumed to be 20 percent until the end of 1980s and 10 percent afterwards, until around 2000. Given the continuous improvements in many contraceptions, such as the IUD, diaphragms, and introduction of new ones, for example the patch, a failure rate of 5 percent is assumed for other methods since 2000.

The last column in Table 29.6 gives annual failure rate across all contraceptive technologies. This series is plotted in Fig. 29.12. To do this, an average is computed over the effectiveness of each method of birth control listed in Table 29.6. When doing this each practice is weighted by its yearly frequency of use, as shown in Table 29.5. 


\begin{tabular}{|c|c|c|c|c|c|c|}
\hline \multicolumn{7}{|c|}{ Effectiveness of Contraception (annual failure rates), \% } \\
\hline Period & None & Pill & Condom & Withdrawal & Other & All (technology) \\
\hline $1900-59$ & 85.0 & - & 45.0 & 59.2 & 50.0 & 72.05 \\
\hline 1960-64 & 85.0 & 7.5 & 17.5 & 22.5 & 20.0 & 59.04 \\
\hline $1965-69$ & 85.0 & 7.5 & 17.5 & 22.5 & 20.0 & 53.79 \\
\hline 1970-74 & 85.0 & 7.5 & 17.5 & 22.5 & 20.0 & 54.29 \\
\hline 1975-79 & 85.0 & 7.5 & 17.5 & 22.5 & 20.0 & 52.81 \\
\hline $1980-82$ & 85.0 & 7.5 & 17.5 & 22.5 & 20.0 & 48.25 \\
\hline $1983-88$ & 85.0 & 3.4 & 11.0 & 20.5 & 20.0 & 36.76 \\
\hline $1985-89$ & 85.0 & 3.4 & 11.0 & 20.5 & 10.0 & 35.73 \\
\hline 1990-94 & 85.0 & 5.5 & 14.5 & 20.5 & 10.0 & 34.63 \\
\hline $1995-99$ & 85.0 & 5.5 & 14.5 & 23.0 & 10.0 & 32.69 \\
\hline 2000-04 & 85.0 & 8.0 & 15.0 & 27.0 & 5.0 & 30.76 \\
\hline 2005-08 & 85.0 & 8.0 & 15.0 & 27.0 & 5.0 & 25.38 \\
\hline 2010-14 & 85.0 & 9.0 & 9.0 & 22.0 & 5.0 & 28.63 \\
\hline $2015-17$ & 85.0 & 7.0 & 7.0 & 20.0 & 5.0 & 18.39 \\
\hline
\end{tabular}

\section{References}

Aiyagari, S.R., Greenwood, J., Guner, N., 2000. On the state of the union. Journal of Political Economy 108 (2), 213-244.

Akerlof, G., Yellen, J.L., Katz, M.L., 1996. An analysis of out-of-wedlock childbearing in the United States. The Quarterly Journal of Economics 111 (2), 277-317.

Albanesi, S., Olivetti, C., 2016. Gender roles and medical progress. Journal of Political Economy 124 (3), 650-695.

Angrist, J., 2002. How do sex ratios affect marriage and labor markets? Evidence from America's second generation. The Quarterly Journal of Economics 117 (3), 997-1038.

Arias, E., 2004. United States Life Tables, 2001. National Vital Statistics Reports, vol. 52 (14). National Center for Health Statistics, Hyattsville, MD.

Becker, G.S., 1991. A Treatise on the Family, enlarged edition. Harvard University Press, Cambridge, MA.

Becker, G.S., 1993. Nobel lecture: the economic way of looking at behavior. Journal of Political Economy 101 (3), 385-409.

Belsky, R., 1975. Vaginal Contraceptives: A Time for Reappraisal? Population Reports, Series H, vol. 3. George Washington University Medical Center.

Billari, F.C., 2019. Technology and Family: The Digital Revolution. Department of Social and Political Sciences, Bocconi University.

Bisin, A., Verdier, T., 2001. The economics of cultural transmission and the dynamics of preferences. Journal of Economic Theory 97 (2), 298-319.

Bronson, M.A., Mazzocco, M., 2017. Cohort Size and the Marriage Market: Explaining Nearly a Century of Changes in U.S. Marriage Rates. Georgetown University. Unpublished Paper.

Bronson, M.A., Mazzocco, M., 2018. Cohort Size and the Marriage Market: What Explains the Negative Relationship? Georgetown University. Unpublished Paper.

Browning, M., Chiappori, P.-A., Weiss, Y., 2014. Economics of the Family. Cambridge University Press, New York. 
Carter, S.B., et al. (Eds.), 2006. Historical Statistics of the United States: Millennial Edition. Cambridge University Press, New York.

Caucutt, E.M., Cooley, T.F., Guner, N., 2013. The farm, the city, and the emergence of social security. Journal of Economic Growth 18 (1), 1-32.

Caucutt, E.M., Guner, N., Knowles, J.A., 2002. Why do women wait? Matching, wage inequality, and the incentives for fertility delay. Review of Economic Dynamics 5 (4), 815-855.

Caucutt, E.M., Guner, N., Rauh, C., 2018. Is Marriage for White People? Incarceration, Unemployment, and the Racial Marriage Divide. Western University. Unpublished paper.

Cavalcanti, T., Kocharkov, G., Santos, C., 2020. Family planning and development: aggregate effects of contraceptive use. Economic Journal. https://doi.org/10.1093/ej/ueaa070.

Charles, K.K., Luoh, M.C., 2010. Male incarceration, the marriage market, and female outcomes. The Review of Economics and Statistics 92 (3), 614-627.

Chiappori, P.-A., Iyigun, M., Weiss, Y., 2009. Investment in schooling and the marriage market. The American Economic Review 99 (5), 1689-1713.

Chiappori, P.-A., Salanié, B., Weiss, Y., 2017. Partner choice, investment in children, and the marital college premium. The American Economic Review 107 (8), 2109-2167.

Cole, H.L., Ohanian, L.E., 2004. New deal policies and the persistence of the Great Depression: a general equilibrium analysis. Journal of Political Economy 112 (4), 779-816.

Cooley, T.F., Ohanian, L.E., 1997. Postwar British economic growth and the legacy of Keynes. Journal of Political Economy 105 (3), 439-472.

Curtin, S.C., Ventura, S.J., Martinez, G.M., 2014. Recent Declines in Nonmarital Childbearing in the United States. NCHS Data Brief, vol. 162. National Center for Health Statistics, Hyattsville, MD.

Cutright, P., 1972. Illegitimacy in the United States: 1920-1968. In: Robert, C.F., Parke Jr., R. (Eds.), Demographic and Social Aspects of Population Growth, Vol. 1, U.S. Commission on Population Growth and the American Future. Government Printing Office, Washington, D.C., pp. 376-438.

Doepke, M., Zilibotti, F., 2008. Occupational choice and the spirit of capitalism. The Quarterly Journal of Economics 123 (2), 747-793.

Edlund, L., Machado, C., 2015. How the other half lived: marriage and emancipation in the age of the Pill. European Economic Review 80 (C), 295-309.

Fernandez-Villaverde, J., Greenwood, J., Guner, N., 2014. From shame to game in one hundred years: an economic model of the rise in premarital sex and its de-stigmatization. Journal of the European Economic Association 12 (1), 25-61.

Galor, O., Klemp, M., 2019. Human genealogy reveals a selective advantage to moderate fecundity. Nature Ecology \& Evolution 3 (5), 853-857.

Gershoni, N., Low, C., 2018a. Older Yet Fairer: How Extended Reproductive Time Horizons Reshaped Marriage Patterns in Israel. The Wharton School, University of Pennsylvania. Unpublished paper.

Gershoni, N., Low, C., 2018b. The Impact of Extended Reproductive Time Horizons on Women's Human Capital Investments: Evidence from Israel's Expansion of Access to IVF. The Wharton School, University of Pennsylvania. Unpublished paper.

Goldin, C., Katz, L., 2002. The power of the Pill: oral contraceptives and women's career and marriage decisions. Journal of Political Economy 110 (4), 730-770.

Greenwood, J., 2019. Evolving Households: The Imprint of Technology on Life. The MIT Press, Cambridge, MA.

Greenwood, J., Guner, N., 2009. Marriage and divorce since World War II: analyzing the role of technological progress on the formation of households. In: Acemoglu, D., Rogoff, K., Woodford, M. (Eds.), NBER Macroeconomics Annual 2008. University of Chicago Press, Chicago, pp. 231-276.

Greenwood, J., Guner, N., 2010. Social change: the sexual revolution. International Economic Review 51 (4), 893-923.

Greenwood, J., Guner, N., Knowles, J.A., 2000. Women on welfare: a macroeconomic analysis. The American Economic Review 90 (2), 383-388. 


\section{Chapter 29 The wife's protector}

Greenwood, J., Guner, N., Kocharkov, G., Santos, C., 2014. Marry your like: assortative mating and income inequality. The American Economic Review: Papers and Proceedings 104 (5), 348-353.

Greenwood, J., Guner, N., Kocharkov, G., Santos, C., 2016. Technology and the changing family: a unified model of marriage, divorce, educational attainment, and married female labor-force participation. American Economic Journal: Macroeconomics 8 (1), 1-41.

Greenwood, J., Guner, N., Vandenbroucke, V., 2017. Family economics writ large. Journal of Economic Literature $55(4), 1346-1434$.

Greenwood, J., Seshadri, A., Vandenbroucke, G., 2005a. The baby boom and baby bust. The American Economic Review 95 (1), 183-207.

Greenwood, J., Seshadri, A., Yorukoglu, M., 2005b. Engines of liberation. The Review of Economic Studies 72 (1), 109-133.

Greenwood, J., Yorukoglu, M., 1997. 1974. Carnegie-Rochester Conference Series on Public Policy 46 (1), 49-95.

Hadar, J., Russell, W.R., 1971. Stochastic dominance and diversification. Journal of Economic Theory 3 (3), 288-305.

Hansen, G.D., Prescott, E.C., 2002. Malthus to Solow. The American Economic Review 92 (4), 1205-1217.

Hatcher, R.A., et al., 2018. Contraceptive Technology. Ardent Media, Inc. and Ayer Company Publishers, New York.

Himes, N.E., 1936. Medical History of Contraception. Williams and Wilkins Company, Baltimore.

Kennes, J., Knowles, J.A., 2019. Single Mothers and Shotgun Weddings. University of Aarhus. Unpublished paper.

Kinsey, A.C., Pomeroy, W.B., Martin, C.E., Gebhard, P.H., 1953. Sexual Behavior in the Human Female. W.B. Saunders Company, Philadelphia, PA.

Knowles, J.A., Vandenbroucke, G., 2019. Fertility shocks and equilibrium marriage-rate dynamics. International Economic Review 60 (4), 1505-1537.

Kopecky, K.A., 2011. The trend in retirement. International Economic Review 52 (2), 287-316.

Kopecky, K.A., Suen, R.M.H., 2010. A quantitative analysis of suburbanization and the diffusion of the automobile. International Economic Review 51 (4), 1003-1037.

Livi-Bacci, M., 2012. A Concise History of World Population. John Wiley \& Sons, Ltd., Chichester, U.K.

Low, H., Meghir, C., Pistaferri, L., Voena, A., 2018. Marriage, Labor Supply and the Dynamics of the Social Safety Net. National Bureau of Economic Research Working Paper 24356.

Martin, J.A., Hamilton, B.E., Osterman, M.J.K., Driscoll, A.K., Mathews, T.J., 2017. Births: Final Data for 2015. National Vital Statistics Reports, vol. 66 (1). National Center for Health Statistics, Hyattsville, MD.

Meyers, C.K., 2017. The power of abortion policy: reexamining the effects of young women's access to reproductive control. Journal of Political Economy 125 (6), 2178-2224.

Moffitt, R.A., 1992. Incentive effects of the U.S. welfare system: a review. Journal of Economic Literature 30 (1), $1-61$.

Moffitt, R.A., Phelan, B.J., Winkler, A.E., 2020. Welfare rules, incentives, and family structure. The Journal of Human Resources 55 (1), 1-42.

Mosher, W.D., Jones, J., 2010. Use of Contraception in the United States: 1982-2008. Vital Health Stat, vol. 23 (29). National Center for Health Statistics, Hyattsville, MD.

Ogburn, W.F., Nimkoff, M.F., 1955. Technology and the Changing Family. Houghton Mifflin, Boston, MA.

Ohanian, L.E., 1997. The macroeconomic effects of war finance in the United States: World War II and the Korean War. The American Economic Review 87 (1), 23-40.

Olivetti, C., 2006. Changes in women's hours of market work: the role of returns to experience. Review of Economic Dynamics 9 (4), 557-587.

Regalia, F., Rios-Rull, J.-V., 2001. What Accounts for the Increase in the Number of Single Households? University of Minnesota. Unpublished paper.

Sanger, M., 1914. Family Limitations. Publisher not identified. Pamphlet.

Santos, C., Weiss, D., 2016. Why not settle down already? A quantitative analysis of the delay in marriage. International Economic Review 57 (2), 425-452. 
Schneider, D., Harknett, K., Stimpson, M., 2018. Job Quality and the Educational Gradient in Entry into Marriage and Cohabitation. Washington Center for Equitable Growth. Unpublished paper.

Shephard, A., 2019. Marriage Market Dynamics, Gender, and the Age Gap. University of Pennsylvania. Unpublished paper.

Stevenson, B., Wolfers, J., 2007. Marriage and divorce: changes and their driving forces. The Journal of Economic Perspectives 21 (2), 27-52.

Tietze, C., 1963. The condom as a contraceptive. Advances in Sex Research 1, 88-102.

Vandenbroucke, G., 2008. The American Frontier: technology versus immigration. Review of Economic Dynamics 11 (2), 283-301.

Vandenbroucke, G., 2014. Fertility and wars: the case of World War I in France. American Economic Journal: Macroeconomics 6 (2), 108-136.

Ventura, S.J., Bachrach, C.A., 2000. Nonmarital Childbearing in the United States, 1940-99. National Vital Statistics Reports, vol. 48 (16). National Center for Health Statistics, Hyattsville, MD.

Wilson, W.J., Neckerman, K.M., 1986. Poverty and family structure: the widening gap between evidence and public policy issues. In: Danziger, S.H., Weinberg, D.H. (Eds.), Fighting Poverty: What Works and What Doesn't. Harvard University Press, Cambridge, MA, pp. 232-259.

Wu, L.L., Martin, S.P., England, P., 2018. Reexamining trends in premarital sex in the United States. Demographic Research 38, 727-736. 